\title{
مكانة الممارسة في صناعة تحقيق النصوص: ثلاث صفحات من أيامي مع الثيخ شعيب الأرنؤوط
}

\author{
(D) Ahmed ÜRKMEZa
}

\begin{abstract}
لملخّص
يعتبر التحقيق من أهم الوسائل لخدمة الثقافة الإسلامية والنصوص القديمة. وهو في حد ذاته فنُّ يَستند على خلفية

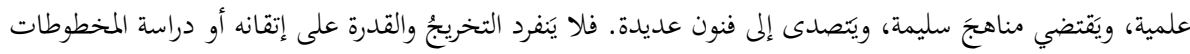

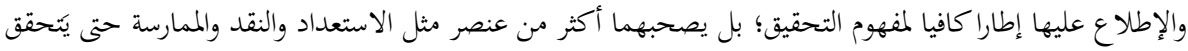

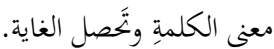
كان الشيخ شعيب الأرنؤوط (ت.2016م) من أبرز أعلام هذا التخصص في العالم الإسلامي، وأكثرِمم نشرا ونشاطا.

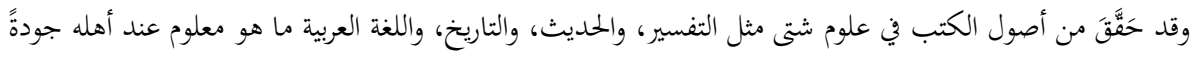

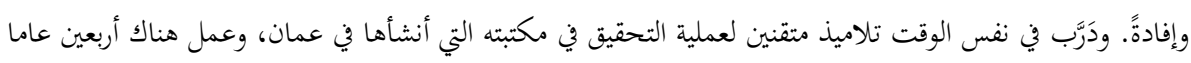

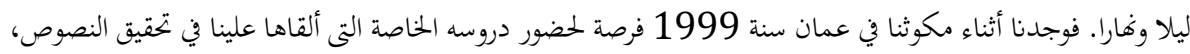
وسجلناها كل أسبوع بإذنه.

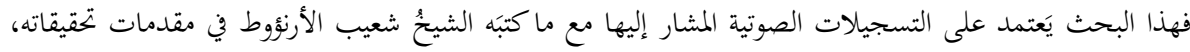

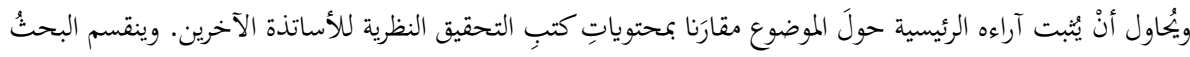

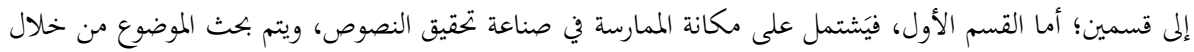

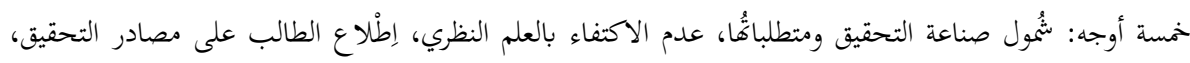

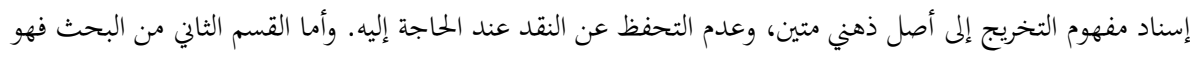

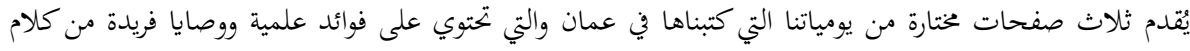

$$
\text { الشيخ شعيب الأرنؤوط رمه الله. }
$$$$
\text { الكلمات المفاتيح: الحديث، تخيق النصوص، التخريج، النقد العلمي، الشيخ شعيب الأرنوط. }
$$ 


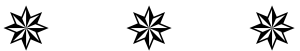 \\ TAHKIK IŞ̧LMINDE UYGULAMANIN YERI VE ÖNEMI: MUHAKKIK ŞUAYB EL-ARNAVUT'TAN ÜÇ HÂTIRA}

Tahkik işlemi, İslâm kültürüne ve eski eserlere emek vermek için en önemli araçlardan birisi olarak görülmektedir. Özü itibarıyla bilimsel birikime dayanan, sağlıklı yöntemleri gerektiren ve birden fazla branşı ilgilendiren bir beceridir. Dolayısıyla ne tahric kavramı ve kusursuz tahric yapabilme yeteneği, ne de yazma eserlere aşinalık tahkik mefhumunun çerçevesini tek başına karşlayabilmekte; bilakis tahkikin anlam ifade etmesi ve amacına ulaşabilmesi için bu iki hususa, yetenek, eleştiri kapasitesi ve uygulamalı çalışma gibi birden fazla faktörün eklenmesi icap etmektedir.

Muhakkik Şuayb el-Arnavut (ö.2016) bu uzmanlık alanının İslâm âlemindeki en önde gelen simalarından ve konuya dair en fazla yayın yapan isimlerindendi. Tefsir, Hadis, Tarih ve Arap Dili gibi birçok branşta kalitesi ve yararı ehlince malum olan temel eserleri tahkik etmişti. Aynı zamanda Amman'da kurduğu tahkik merkezinde kırk yıl boyunca geceli gündüzlü faaliyet göstermiş ve tahkik işlemini üst düzeyde icra eden öğrenciler yetiştirmişti. Biz de 1999 yllında Amman'da bulunduğumuz süreçte bize özel verdiği metin tahkiki derslerine katılma imkânı bulmuş ve bu dersleri her hafta kendisinin izniyle kaydetmiştik.

$\mathrm{Bu}$ araştırma sözü geçen ses kayıtları ile Muhakkik Şuayb el-Arnavut'un tahkik ettiği kitaplara yazdığı mukaddimelere dayanmakta ve kendisinin konuya dair görüşlerini diğer uzmanların teorik tahkik kitaplarında yer verdikleri içeriklerle mukayeseli olarak incelemeyi amaçlamaktadır. Araştırma iki bölüme ayrılmıştır; birinci bölüm metin tahkikinde uygulamanın yeri ve önemini konu edinmekte ve meseleye beş açıdan yaklaşmaktadır: Tahkik sanatının kapsamı ve gereklilikleri, teorik bilgiyle yetinmemek, öğrenciye tahkikin kaynaklarını tanıtmak, tahric kavramını sağlam bir zihnî temele dayandırmak, ihtiyaç hâlinde tenkide başvurmaktan çekinmemek. Araştırmanın ikinci bölümü ise Amman'da kaleme almış olduğumuz ve merhum Muhakkik Şuayb el-Arnavut'un ilmi tespitleri ile eşsiz tavsiyelerini de içeren günlüklerden seçilmiş üç sayfayı kapsamaktadır.

[Geniş Türkçe Öz, çalışmanın sonunda yer almaktadır.]

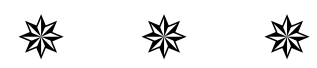

\section{THE PLACE AND IMPORTANCE OF THE APPLICATION IN THE CRITICAL EDITION PROCESS: THREE MEMORIES FROM SHAYKH SHUAIB AL ARNA'UT}

The critical edition process is seen as one of the most important tools to work on Islamic culture and antiquities. In essence, it is a skill based on scientific knowledge, requires healthy methods and involves more than one branch. 
مكانة الممارسة في صناعة تحقيق النصوص: ثلاث صفحات من أيامي مع الشيخ شعيب الأرنؤوط

Therefore, neither the concept of takhrij and the ability to make perfect takhrij examples, nor the familiarity with manuscripts can meet the framework of the notion of critical edition alone; on the contrary more than one factor such as skill, criticism capacity and applied work must be added to these two issues in order for the critical edition to make sense and achieve its purpose.

Shaykh Shuaib al Arna'ut (d. 2016) was one of the most prominent figures in this field of expertise in the Islamic world and one of the most publications on the subject. He had verified basic works of which quality and usefulness were known to its competent in many branches such as Tafsir, Hadith, History and Arabic Language. At the same time, he had worked day and night for forty years in the critical edition center he established in Amman and trained students who performed the investigation process at a high level. During our time in Amman in 1999, we had the opportunity to attend the critical edition lessons he gave us privately and recorded these lessons every week with his permission.

This research is based on the aforementioned sound recordings and the preliminaries written by Shaykh Shuaib al Arna'ut books and aims to examine his views on the subject in comparison with the contents of other experts' theoretical critical edition books. The research is divided into two parts; The first part deals with the place and importance of the application in text analysis and approaches the issue from five angles: The scope and requirements of the art of critical edition, not being content with theoretical knowledge, introducing the student to the sources of the critical edition, basing the concept of the author on a solid mental basis, not hesitating to use criticism when needed. The second part of the research covers three pages selected from the diaries that we wrote in Amman and which include the scientific determinations and unique recommendations of the late Shaykh Shuaib al Arna'ut.

[The Extended Abstract is the end of article.]

$$
\begin{aligned}
& \text { 路路 } \\
& \text { المقدمة } \\
& \text { المقدمة: الحقق الشيخ شعيب الأرنؤوط وأثره البالغ في نشأة الأكاديميين في تركيا }
\end{aligned}
$$

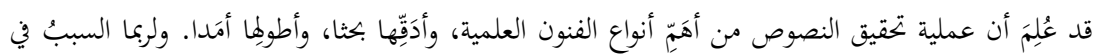

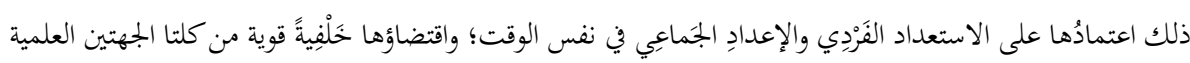

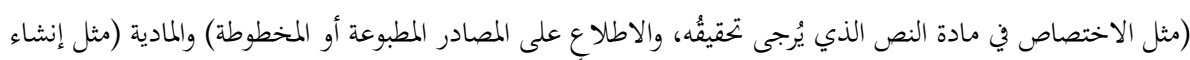

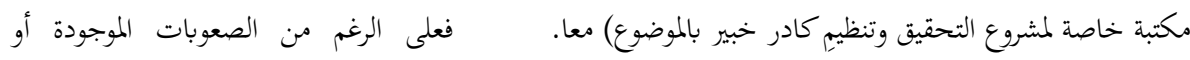

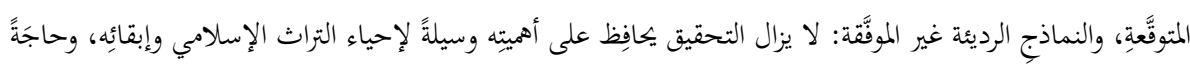

$$
\begin{aligned}
& \text { لتَطَوُرٍ النقد العلمِي ونشرِهِ. }
\end{aligned}
$$




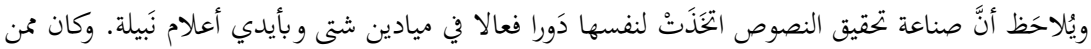

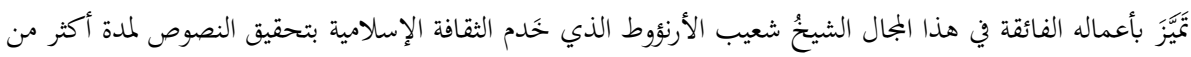

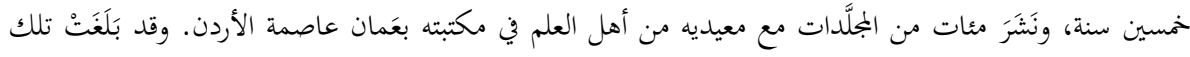

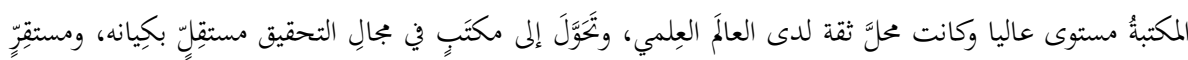
على مَبادئه، ومعروفٍ بجودة منشوراته.

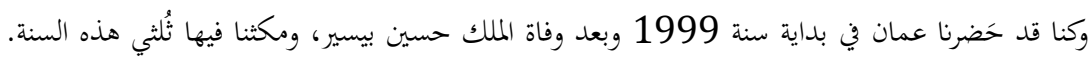

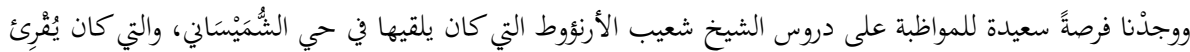

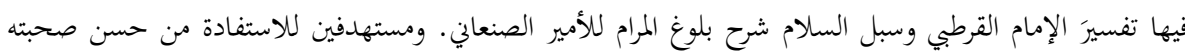

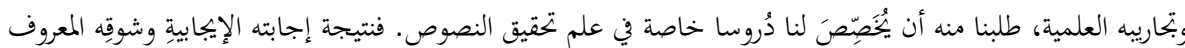

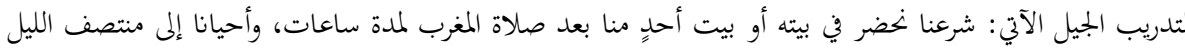

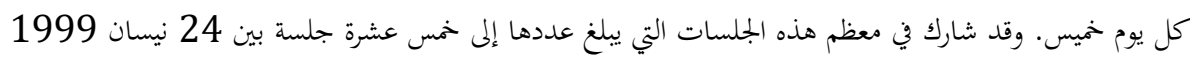

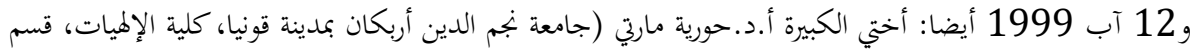

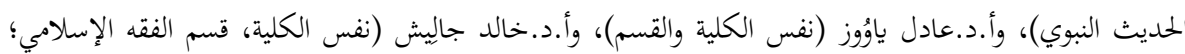
والعميد المؤسس لكلية العلوم الإسلامية في مدينة قَمَمان)، وأ.د.صائم قيادِي (الجامعة الإسلامية العالمية بماليزيا). وقد سَبََّا إلى الاستفادة عن مكتسبات الشيخ شعيب الأرئؤوط في العلوم الإسلامية اثنان من الأكاديميين

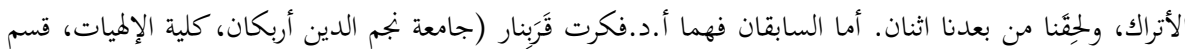

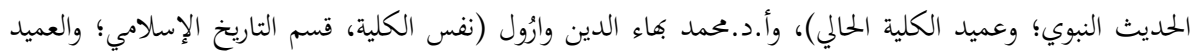

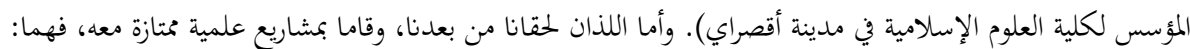

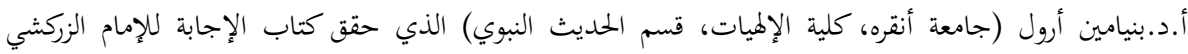

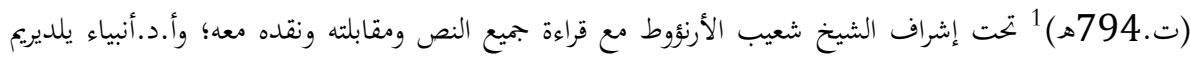

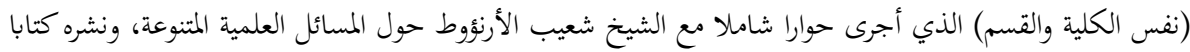

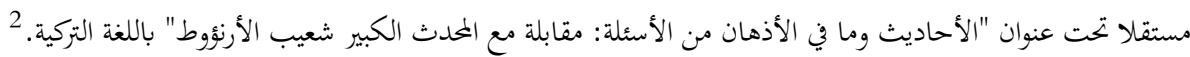

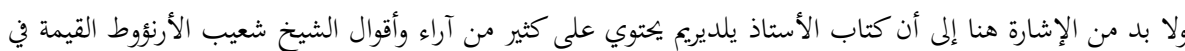

$$
\text { تحقيق النصوص وتخريج الأحاديث أبوابا مفصلا. } 3
$$

وكان الشيخ شعيب الأرنؤوط قد وُلِدَ في دمشق سنة 1928 أحلَ أفرادِ أسرة ألبانية، هاجرَتْ إلى دمشق

1 بدرالدين الزركشي، الإجابة لإيراد ما استدركته عائشة على الصحابة (التحقيق: د.بنيامين أرول؛ التقديم: المحلث شعيب الأرنؤوط)

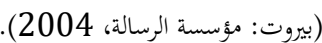

2 Enbiya Yıldırım, Hadisler ve Zihinlerdeki Sorular: Büyük Muhaddis Șayp Arnavut'la Söyleşi (İstanbul: Rağbet Yayınları, 2011).

3 وكان من فضل الأستاذين أرول ويلديريم أفما أدركا الصلاة على الشيخ شعيب الأرنؤوط رحمه الله، وشاركا في دفنه، وباشرا وفق وصيته

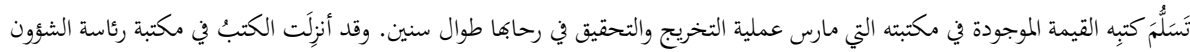

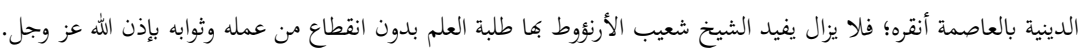


مكانة الممارسة في صناعة تحقيق النصوص: ثلاث صفحات من أيامي مع الشيخ شعيب الأرنؤوط

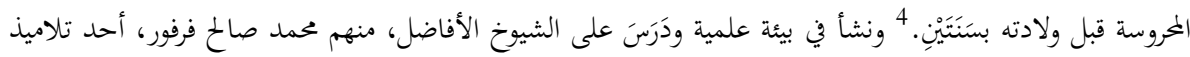

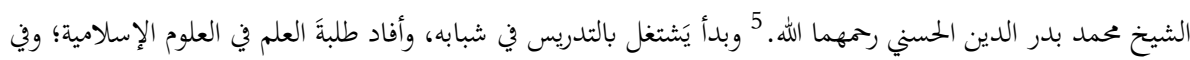

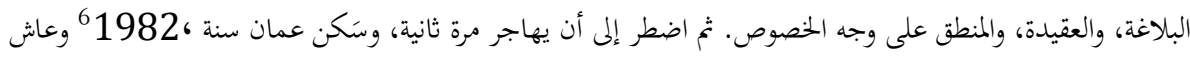

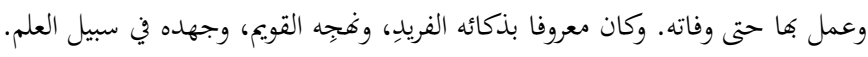

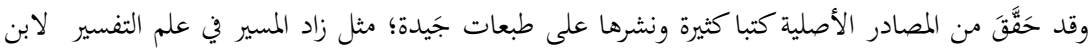

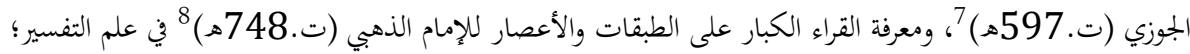

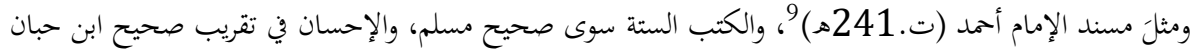

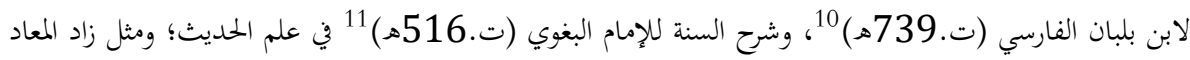

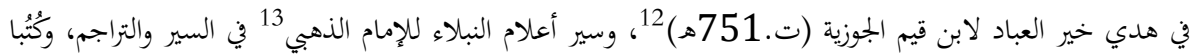
أخرى يَطول إحصاؤها هنا في سطور يسيرة.

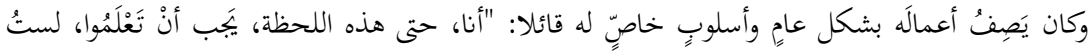

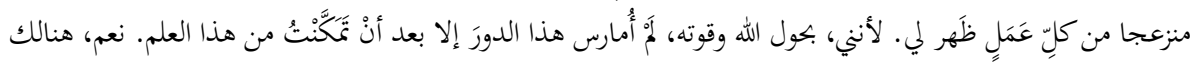

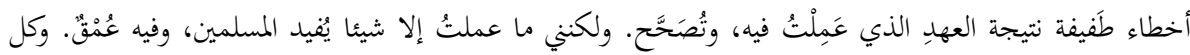

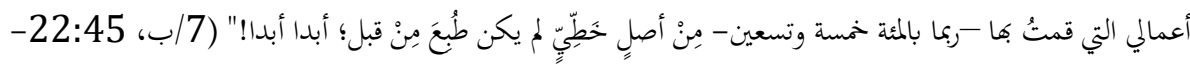

4 Yıldırım, Hadisler ve Zihinlerdeki Sorular: Büyük Muhaddis Şuayp Arnavut'la Söyleşi, 2426.

5 إبراهيم الزبيق، المحلث العلامة الشيخ شعيب الأزئؤط: سيرته في طلب العلم وجهوده في تحقيق التراث (بيروت: دار البشائر الإسلامية،

2012)، 55-60. وانظر لمشايخه أيضا: يلديريم، الأحاديث وما في الأذهان من الأسئلة، ص.

6 Yıldırım, Hadisler ve Zihinlerdeki Sorular: Büyük Muhaddis Şuayp Arnavut’la Söyleşi, 40.

7 جمال الدين أبو الفرج عبد الرمن بن علي ابن الجوزي، زاد المسير في علم التفسير (تحقيق: محمد زهير الشاويش، شعيب الأزئوط، عبد

القادر الأزئوط) (بيروت: المكتب الإسلامي).

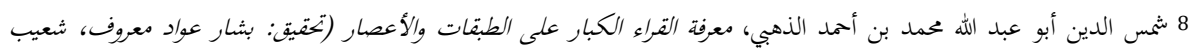

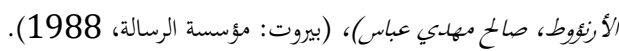

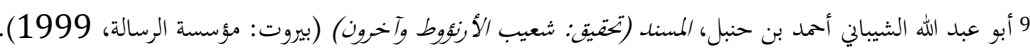

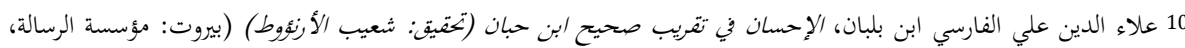

11 الحسين بن مسعود البغوي، شرح السنة (تحقيق: شعيب الأرئوط، محمد زهير الشاويش) (بيروت: المكتب الإسلامي، 1988) 1983).

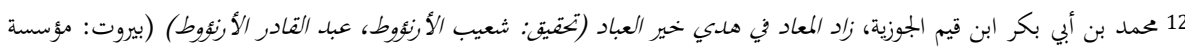

الرسالة، 1998).

13 شمس الدين أبو عبد الله محمد بن أحمد الذهبي، سير أعلام النبلاء (تحقيق: شعيب الأنؤوط وآخرون) (بيروت: مؤسسة الرسالة،

14 وانظر لقائمة كاملة في آثاره: الزبيق، المحلدث العلامة الشيخ شعيب الأرنؤوط: سيرته في طلب العلم وجهوده في تحقيق التراث، 218-

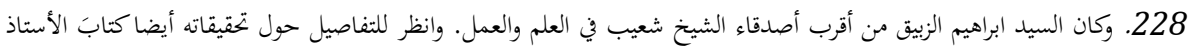


فهذا البحث يَعتمد على ما يتعلق بالعنوان من المعلومات التي سمعناها من الشيخ شعيب الأرنؤوط في تلك

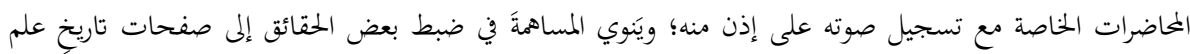
التحقيق.

\section{1. مكانة الممارسة في صناعة تحقيق النصوص}

يَكتوي القسم الأول على خمسة عناوين فرعية، مشتركَة في التأكيد على أهمية الممارسة العملية في التحقيق.

\section{1. شُمول صناعة التحقيق ومثطلباتُما}

لا شك أن للتحقيق مبادئ يدور عليها، وإطارا شاملا لعناصر عِدة يجب تعبينُها والحِفاظُ عليها. وقد اتفق

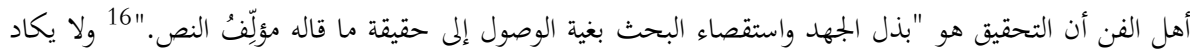

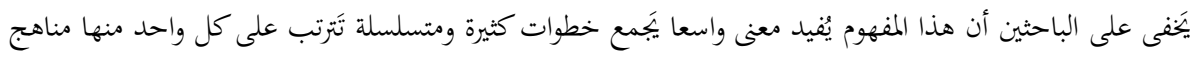
عديدة. 17

وكان الشيخ شعيب يَفصل بدقة بين مراحل التحقيق، ويُعَدِّر قدر كل منها، ويُحَدِّد محورَها ومجراها؛ ويُفَرِّق بين

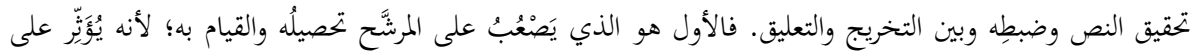

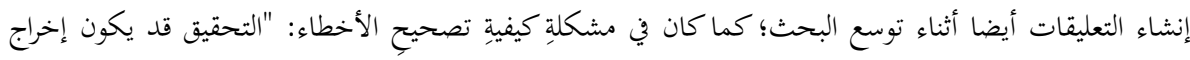

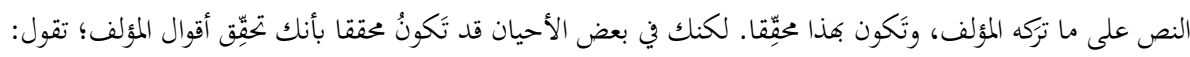

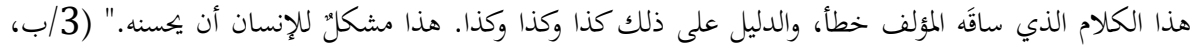

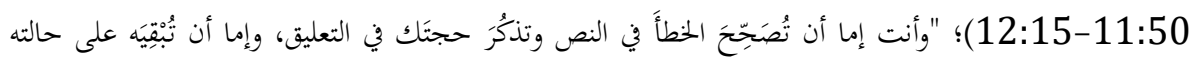

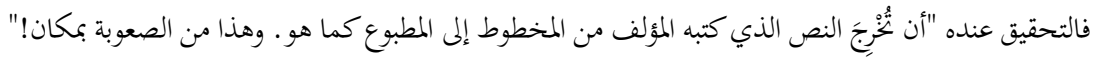

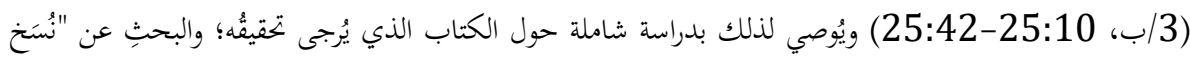

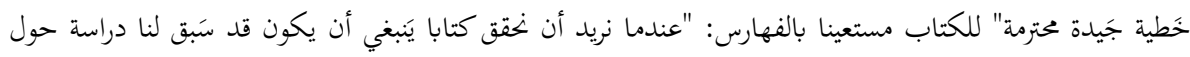

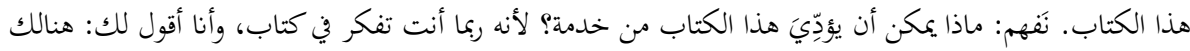

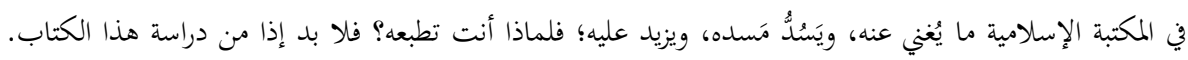

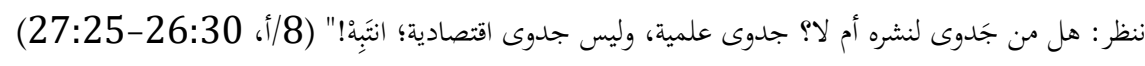
وكان يَرى جودةً النسخة الخطية في غاية الأهمية، ويقول مشيرا إلى حالة النُسخ المعتمد عليها في تحقيقهم لمسند

15 اخترنا في هذا البحث أن نشير إلى كلمات الشيخ شعيب الأرنؤوط الموجودة في التسجيلات الصوتية على هذا النمط. فالرقم الأول

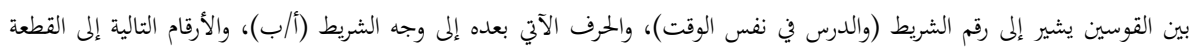

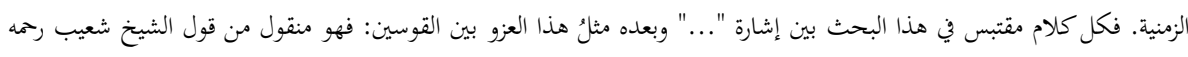


مكانة الممارسة في صناعة تحقيق النصوص: ثلاث صفحات من أيامي مع الشيخ شعيب الأرنؤوط

الإمام أحمد، والنُسخخ الميسَّرة للمحقق المتقدم لنفس الكتاب: "نخن حَصلنا على خخطوطات جيدة لمُ تَقَّعْ له. من الأمور

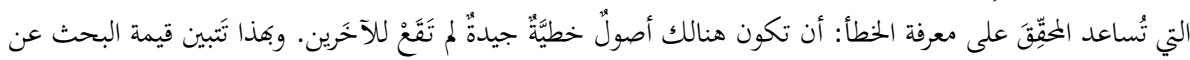
الأصول الخطية." (7/ب، 31:15-31:40) وكان يقول أيضا: "لا تيأسوا عن نسخة خطية تبحثون عنها أبدا"،

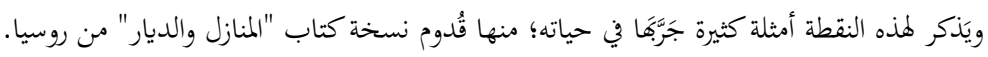

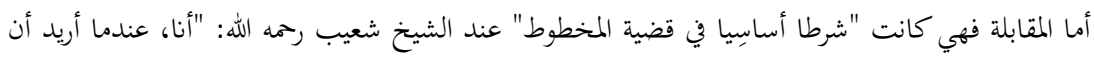

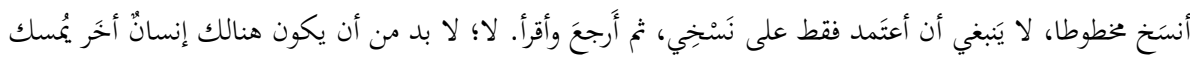

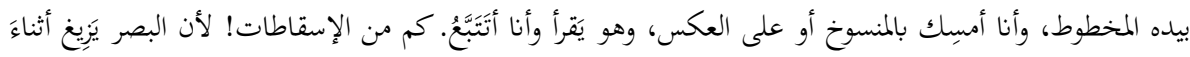

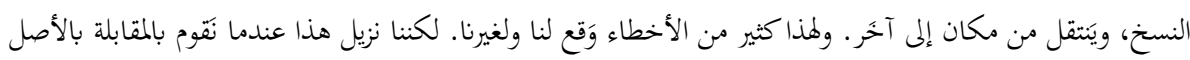

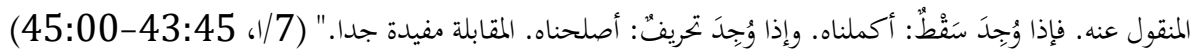

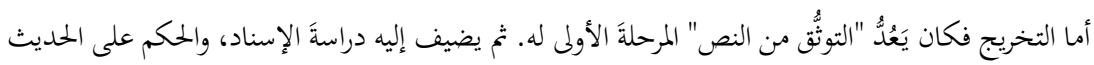

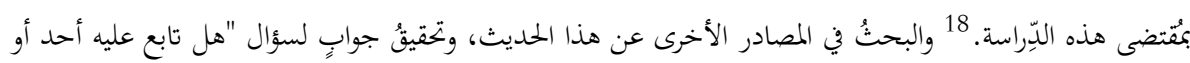

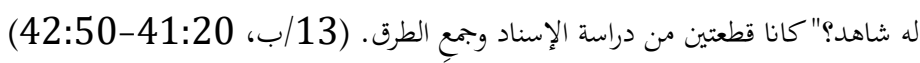

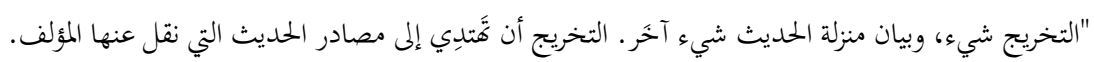

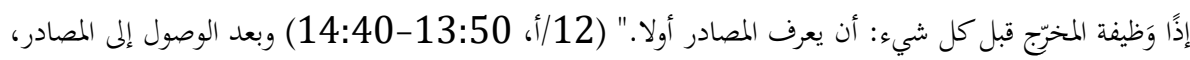

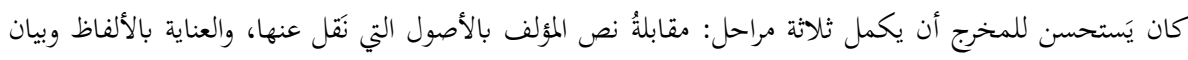

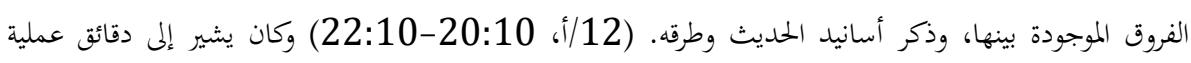

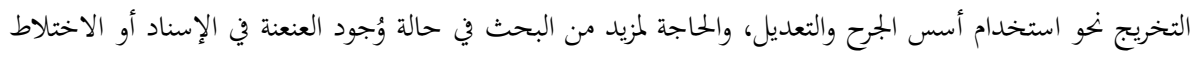

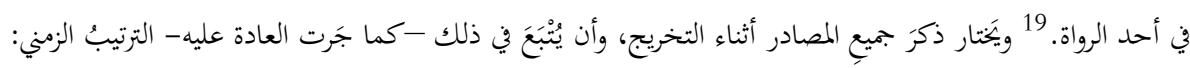

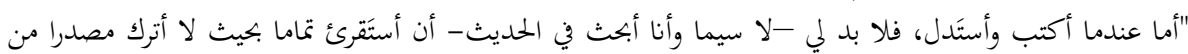

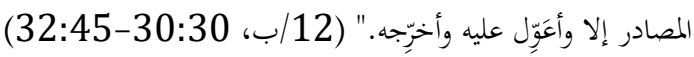

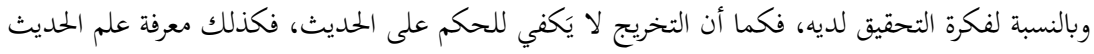

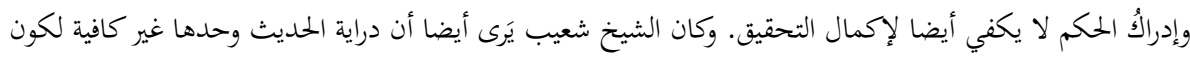

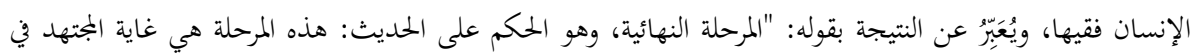
علم الحديث." (13/أ، 24:10-24:25) فكانه كان مقتنعا أن الممارسة العملية هي الخور الأساسي لتطور هذه الصناعة. وقد سَجلنا من كلامه أيضا:

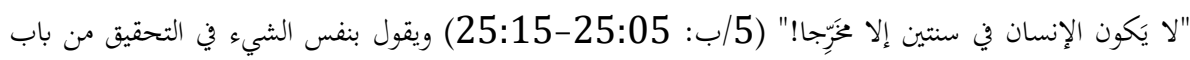

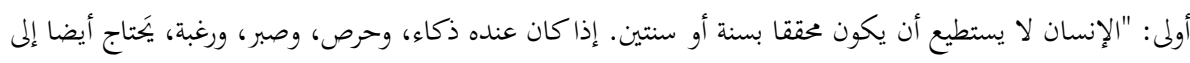

18 انظر للتفاصيل حول دراسة الإسناد والحكم على الحديث: محمود الطحان، أصول التخريج ودراسة الأسانيد (الرياض: مكتبة المعارف

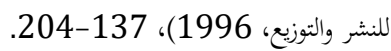
19 Yıldırım, Hadisler ve Zihinlerdeki Sorular: Büyük Muhaddis Şuayp Arnavut'la Söyleşi, 135140. 
زمن طويل. والزمن الطويل هو الذي يُكسبه المران." (3/ب، 19:40-20:10) فمن هذا المنطلق، كان يقول:

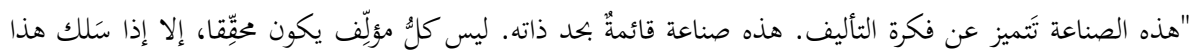

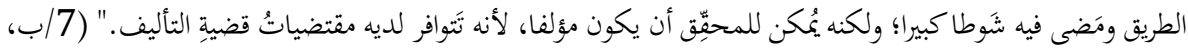

(04:22-03:50

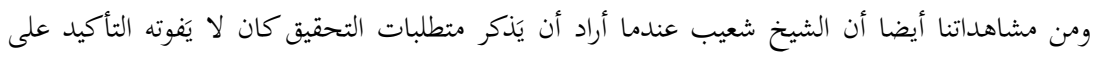

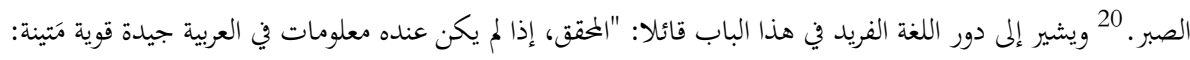

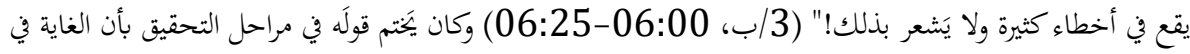

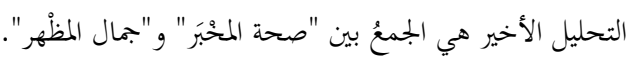

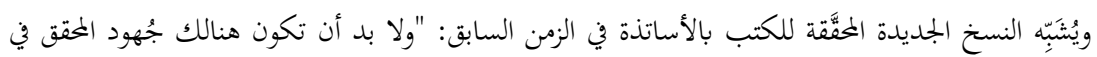

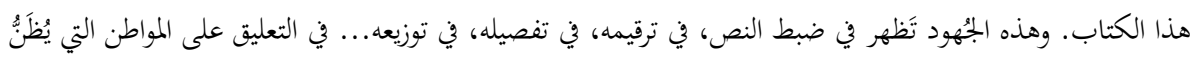

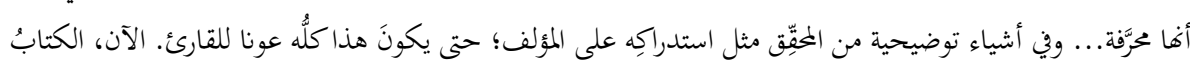

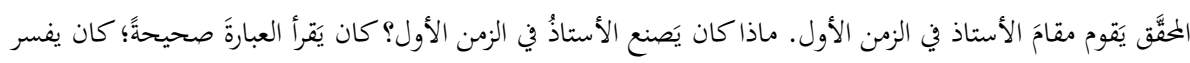

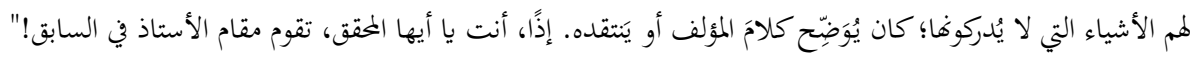

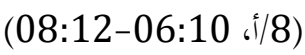

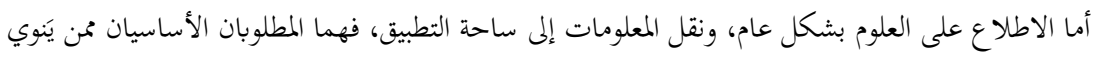

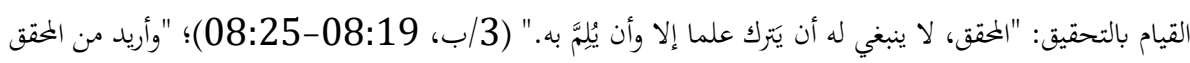

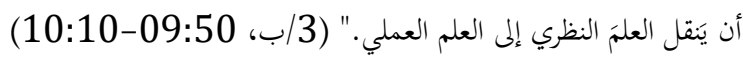

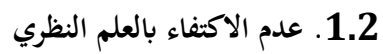

وكان عدم اكتفاء طالب الجامعة بالعلم النظري ومباشرتُه عملية التحقيق بالذات مأما أكَّده الشيخ شعيب دائما.

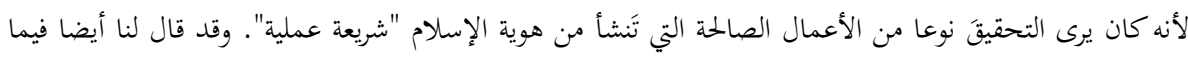

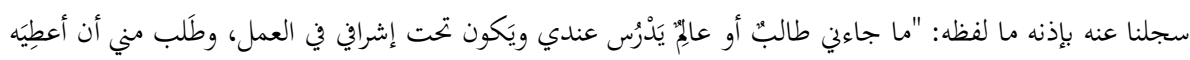

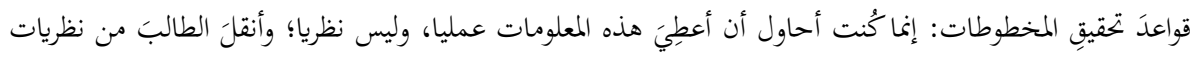

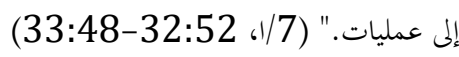

وكأن تحديد الشيخ شعيب لعلم تحقيق النصوص بأنه علمُ عملي، وتفضيلَه إياه على العلم النظري كان يمنعه

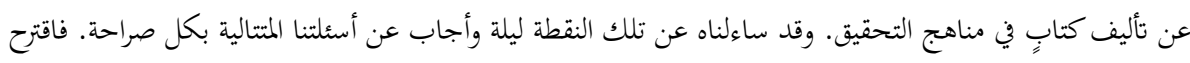
عليه أحلُ الأستاذة أولا أن يكتب كتابا في فئ هذا الموضوع، فأجابه قائلا:

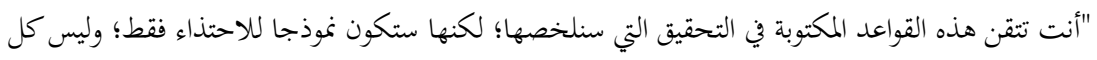

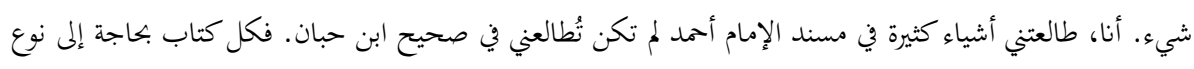


مكانة الممارسة في صناعة تحقيق النصوص: ثلاث صفحات من أيامي مع الشيخ شعيب الأرنؤوط

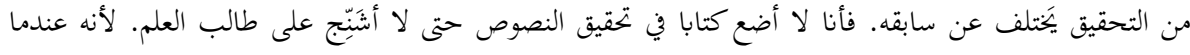

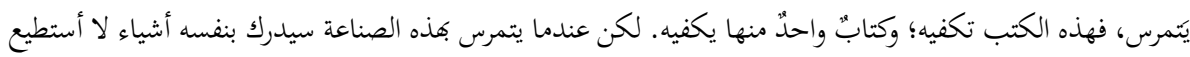

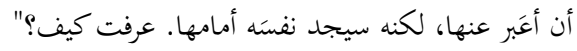

وتكلمت هنا وقلت: "لو كتبتم ذكرياتكم في عالم التحقيق!" فأجاب عن كلامي هذا بقوله الذي أضحكنا

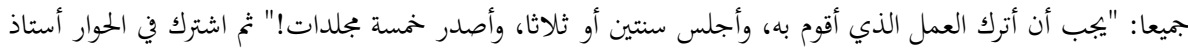

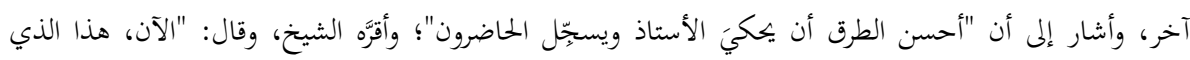

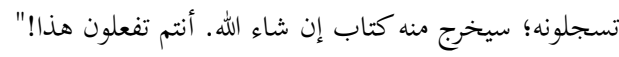

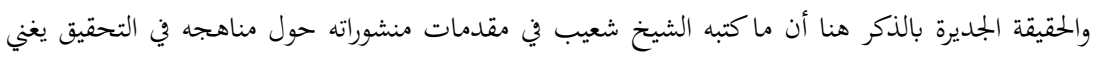

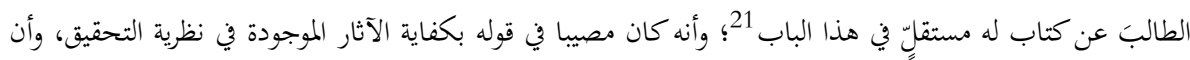

تلك الصنعة تُكسب في كل خطوة بعدا جديدا.

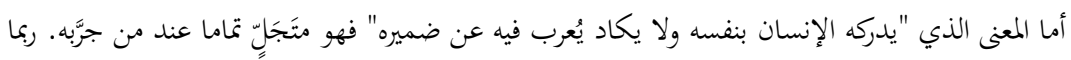

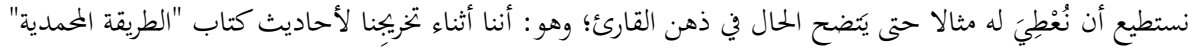

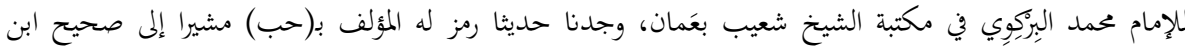

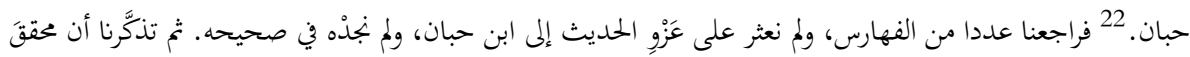

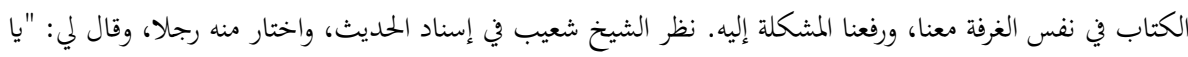

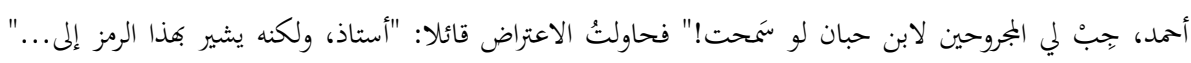

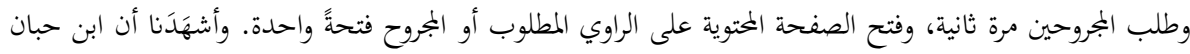

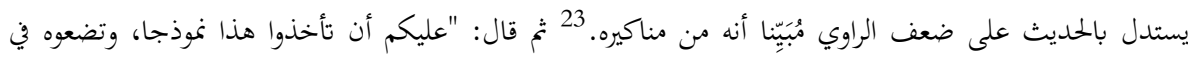

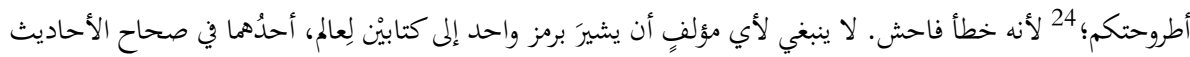

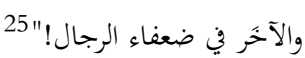

21 وانظر مثالا على ذلك: أهمد بن حنبل, المسند (تحتقيق: شعيب الأزئوط والآخرون)، 33/1-175; ابن بلبان, الإحسان في تقريب

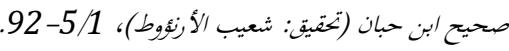

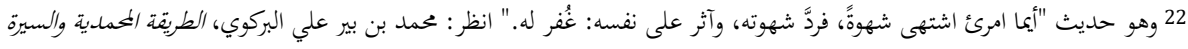

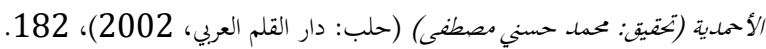

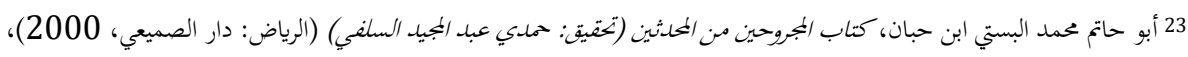

41/2 (ترجمة عمرو بن خالد الواسطي).

24 Huriye Martı, Birgili Mehmed Efendi'nin Hadisçiliği ve et-Tarikatü'l-Muhammediyye (Tahkik ve Tahlil) (Konya: Selçuk Üniversitesi Sosyal Bilimler Enstitüsü, Doktora Tezi, 2005), 221-222; Ahmed Ürkmez, Kadızadeliler-Sivasiler Tartışmalarının Hadis İlmine Etkisi ve İdrakü'l-Hakika Örneği (Konya: Selçuk Üniversitesi Sosyal Bilimler Enstitüsü, Yüksek Lisans Tezi, 2000), 106-108.

25 كما نرى هذا أسلوبا مطردا في مصنفات العلماء السابقين. فانظر لاستخدام رمز (ت) للترمذي، و(تم) له في "الشمائل"؛ ورمز (س)

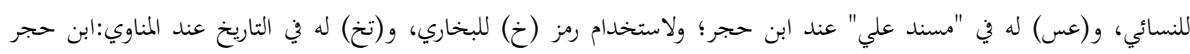


هذه كانت نتيجة الممارسة بالتحقيق. وإلا فنحن كنا ندري ما في الصحاح من الخصائص، وفي كتب الجرح

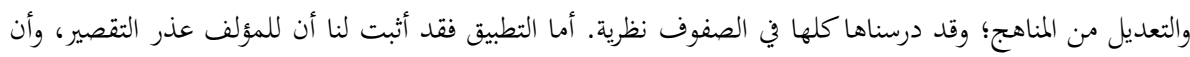
على المحق واجب التنبه والتنبيه.

\section{3. إطُلاع الطالب على مصادر التحقيق}

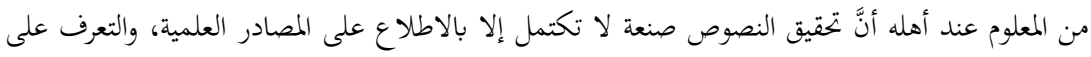

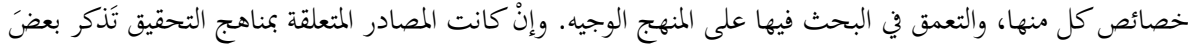

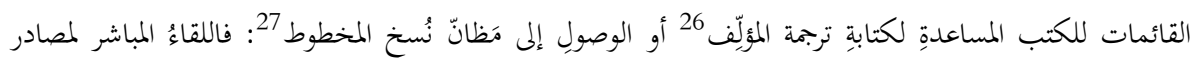

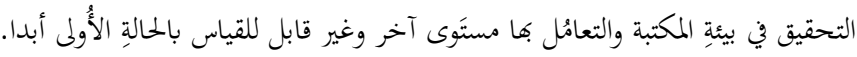

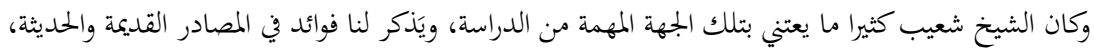

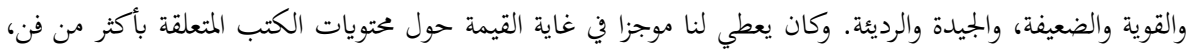

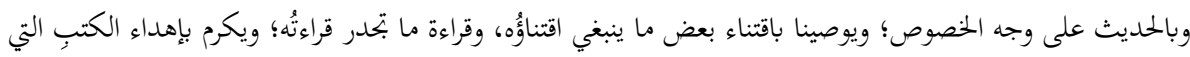

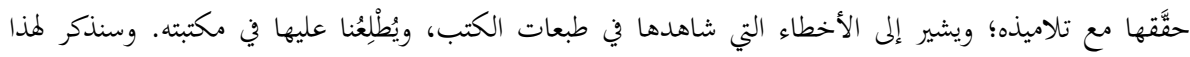

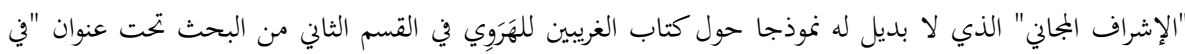

وقد قدم لنا معلومات في بداية دروسه معنا حول ما كتبه الأساتذة الغترمون من الكتب النظرية في مناهج

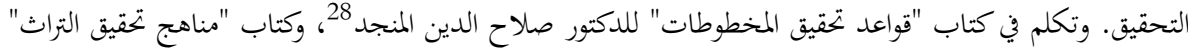

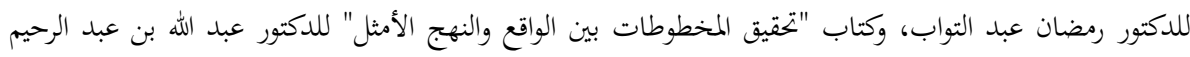

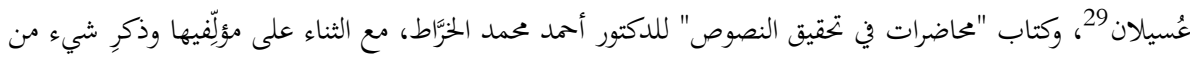

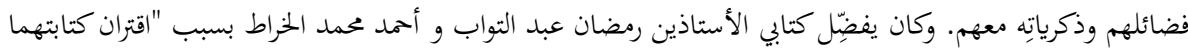

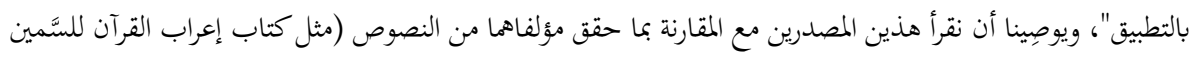

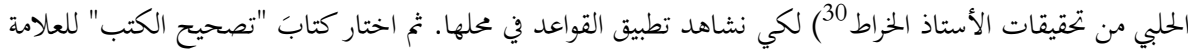

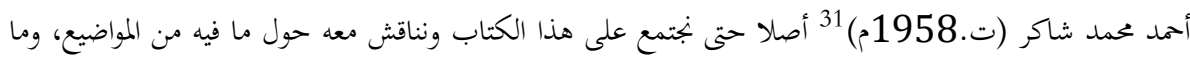

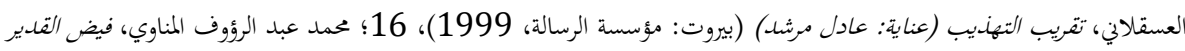

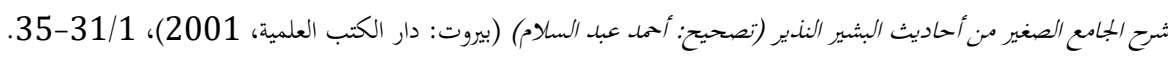

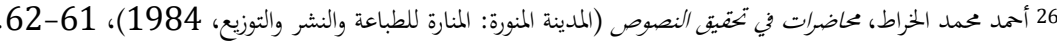

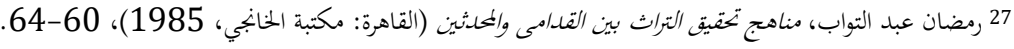

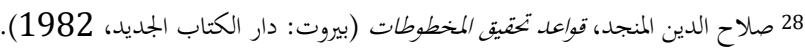

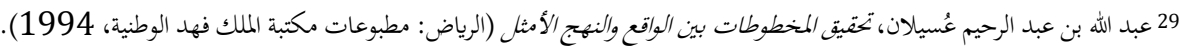

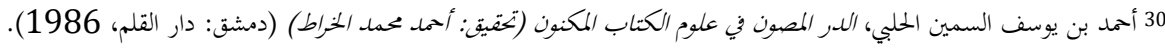


مكانة الممارسة في صناعة تحقيق النصوص: ثلاث صفحات من أيامي مع الشيخ شعيب الأرنؤوط

ليس فيه من بحاربه الشخصية.

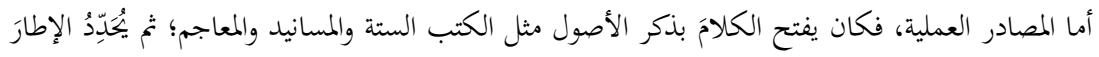

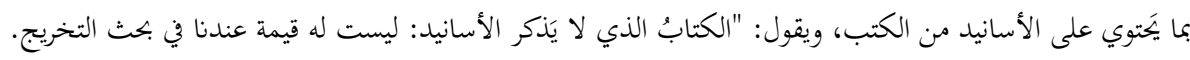

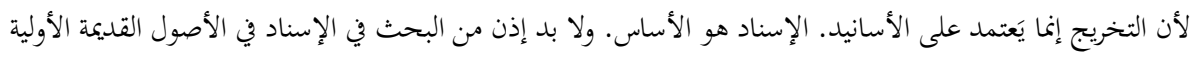

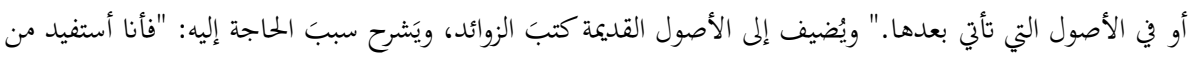

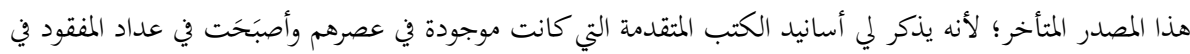

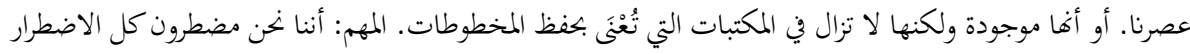

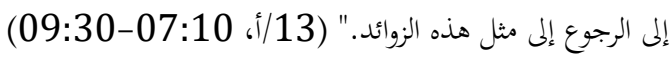

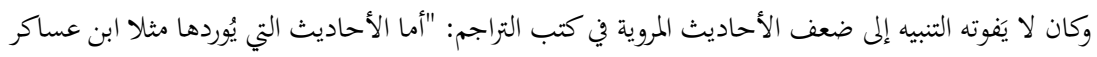

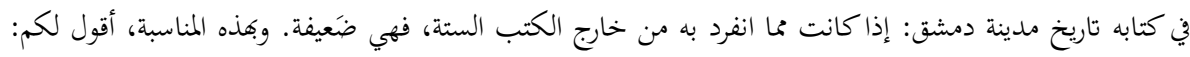

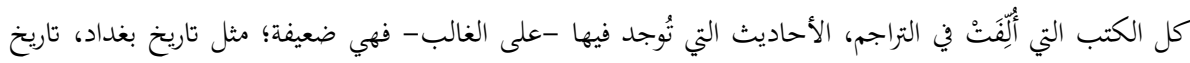

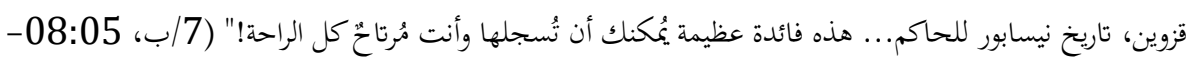

(08:55

وكان من بركة المكتبة أيضا أنْ خظى بمعلومات مباشرة حولَ المصادر التي يَستمر تحقيقها على يد الشيخ شعيب

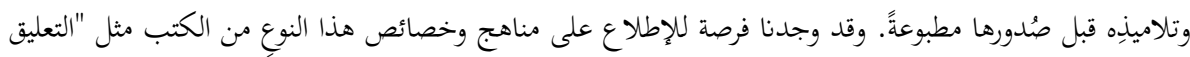

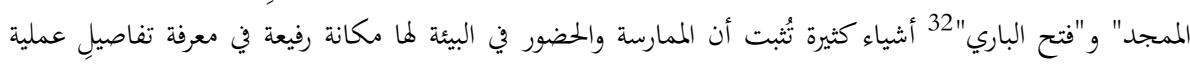

التحقيق.

\section{4. إسناد مفهوم التخريج إلى أصل ذهني متين}

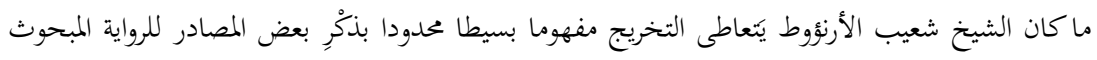

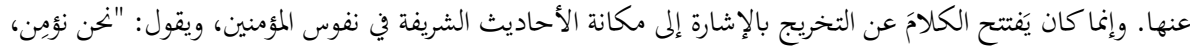

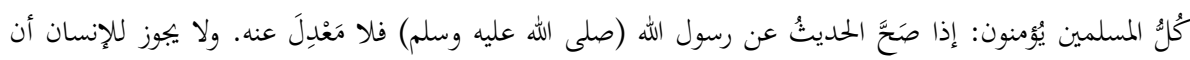

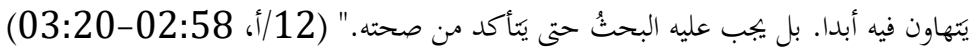

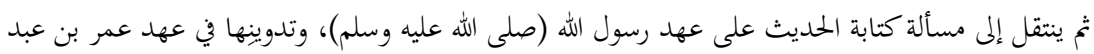

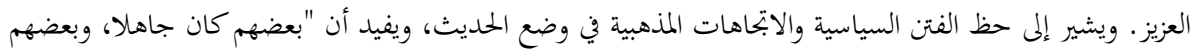

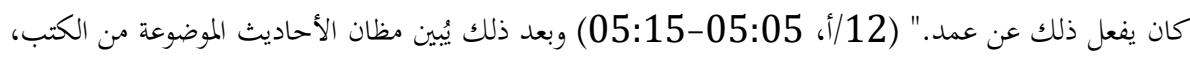

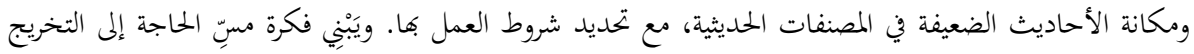

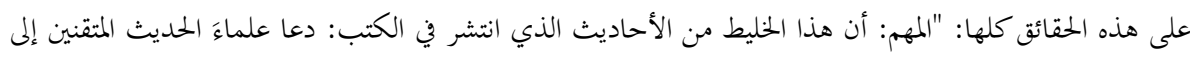

32 وقد طُع الكتاب الأول سنة 2011، والثاني سنة 2013 بتحقيقهم. انظر :محمد بن عبد الحي اللكنوي، التعليق الممجد على موطأ

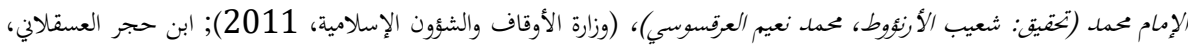

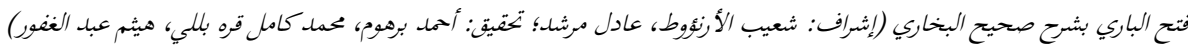


أن يقوموا بتخريج هذه الأحاديث، ويُيِّنوا منزلتها من الصحة أو الضعف، ويدوِنوها في الكتب." (12/أ، 10:58-

وكان من مزاياه أيضا أن يُوضِّح شيئا من الحلفيات التاريخية للنصوص القديمة، ويشيرَ إلى أن كثيرا من العلماء

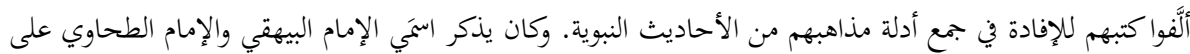

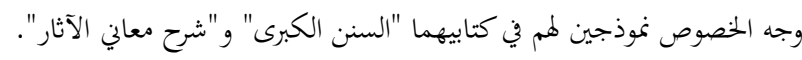
وكان يؤَّدّ على نفس الواقع في تأليف كتب التخريج، ويقول: "الفقهاء -رمهمم الله- لاحخظوا أن الاستلال

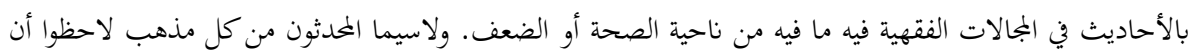

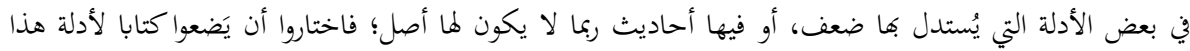

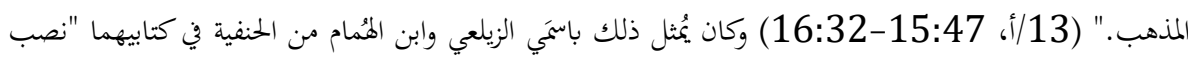
الراية لأحاديث الهداية" و "فتح القدير". 33

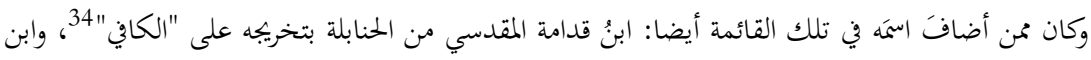

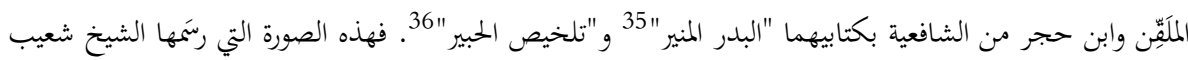

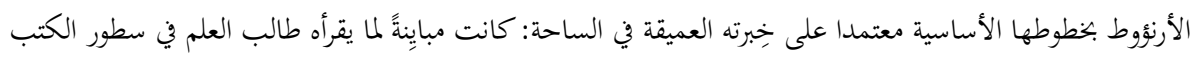

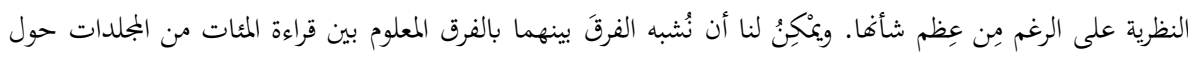
المنطقة، وتاريخها، وأهمية منابع المياه الموجودة فيها؛ وبين وقفٍٍٍ لا تَستغرق أكثرَ من ساعة أمام طبرية والجولان.

1.5. عدم التحفظ عن النقد عند الحاجة إليه

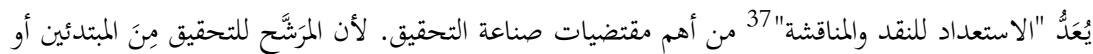

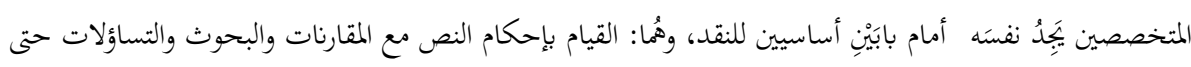

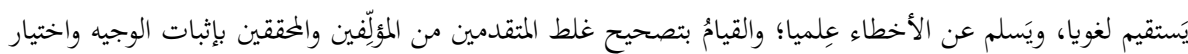

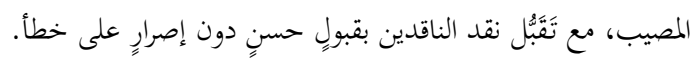

ربما كان من أهم مزايا الشيخ شعيب الأرنؤوط وَلَعُه بتععيل المهارة العقلية، واستخدامِها فِ سبيل الوصول إلى

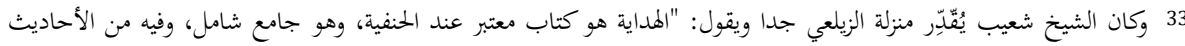

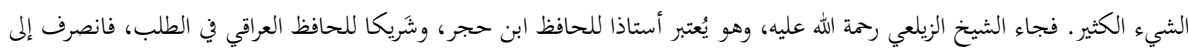

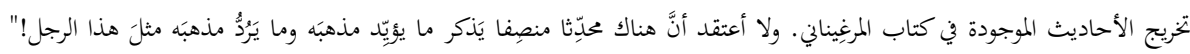

34 عبد الله بن أحمد ابن قدامة، الوافي في تخريج أحاديث الكافي (تخريج: خالد بن ضيف الله) (دمشق: دار المنهاج القويم، 2017: 20130).

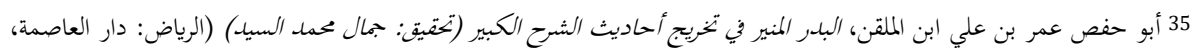

36 ابن حجر العسقلاني، تلخيص الحبير في تخريج أحاديث الرفعي الكبير (اعتناء: حسن بن عباس بن قطب) (مكة المكرمة: مؤسسة

37 وانظر لتفاصيل البحث نظريا: الخراط، محاضرات في تحقيق النصوص ،20. 
مكانة الممارسة في صناعة تحقيق النصوص: ثلاث صفحات من أيامي مع الشيخ شعيب الأرنؤوط

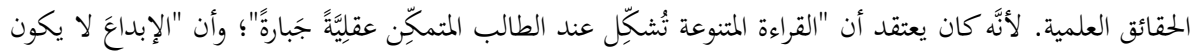

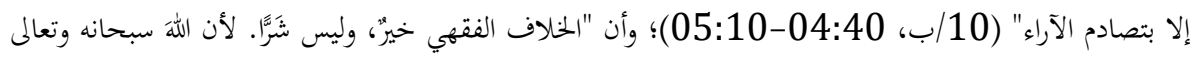

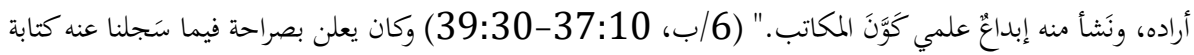

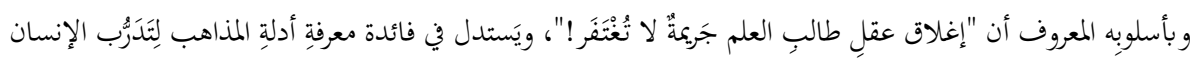
وافتتاح ذهنه بكلام الإمام النووي في مقدمة كتابه "البمموع". 38

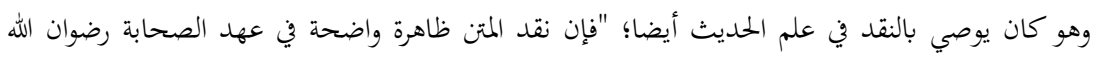

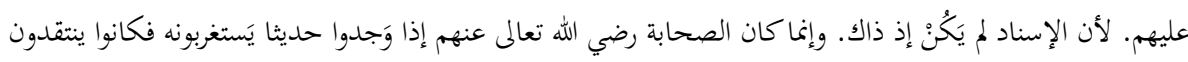

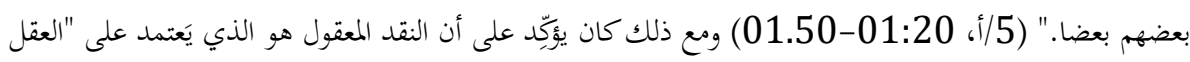

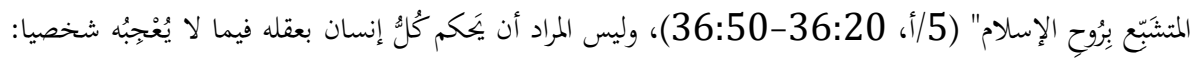

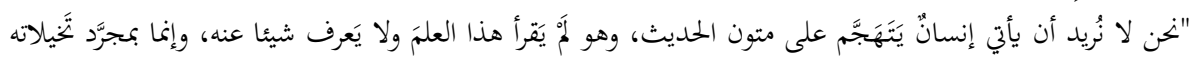

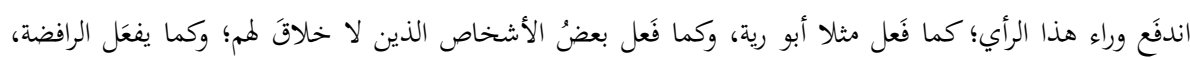

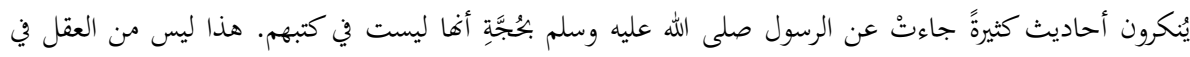

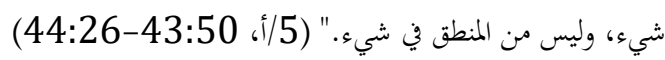

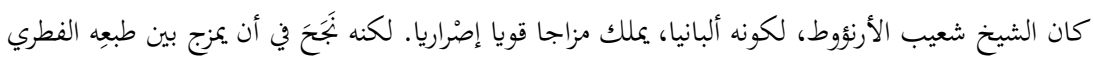

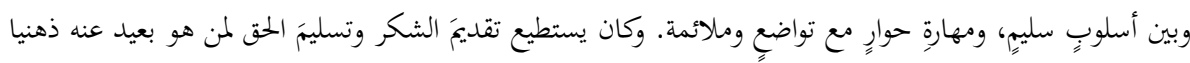

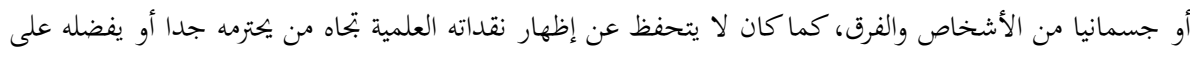

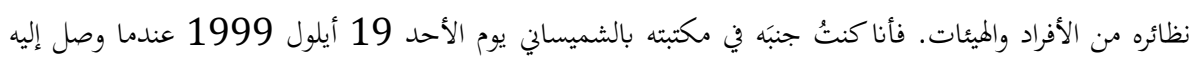

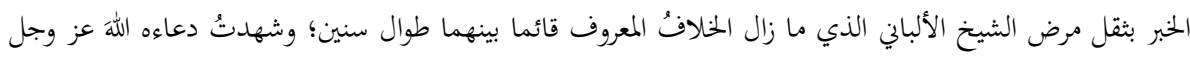

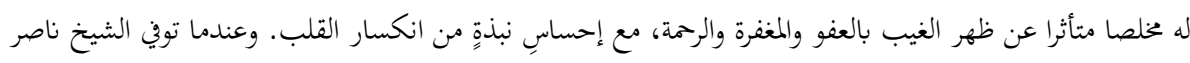

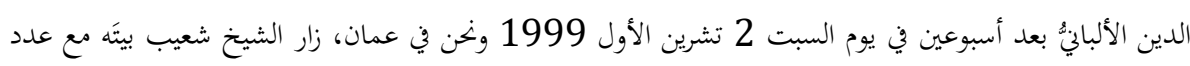
من تلاميذه، وقدم عزاءه لأولاده. - مان.

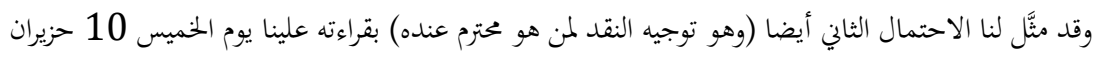

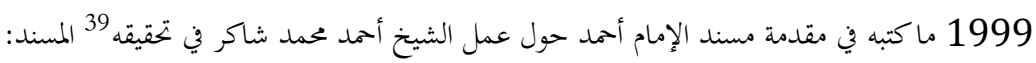

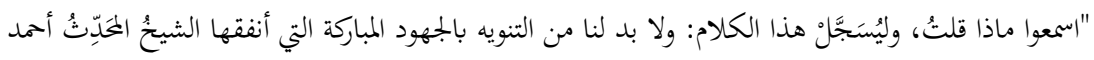

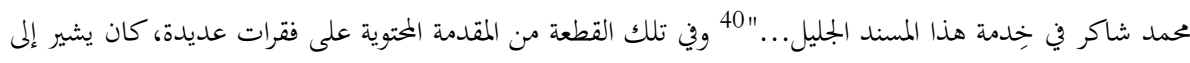

38 وهو قوله رحمه الله: "واعلم أن معرفة مذاهب السلف بأدلتها من أهم ما يحتاج إليه. لأن اختلافهم في الفروع رمة. وبذكر مذاهبهم

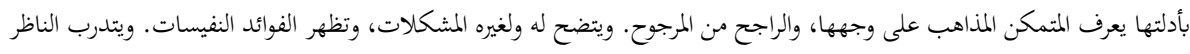

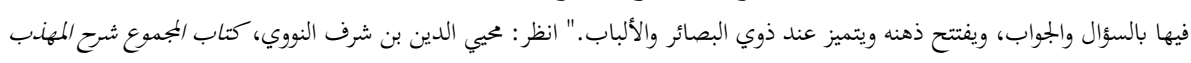

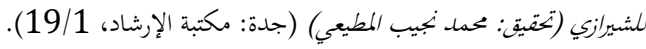

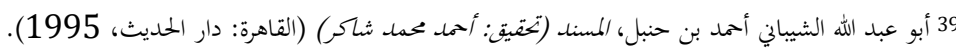

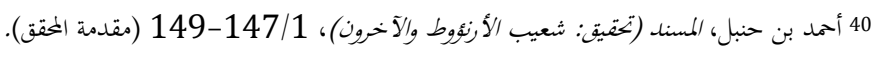


أخطاءٍ سلفِه المحقق الفاضل والحبيب عنده، ويضيف أشياء خارج النص المطبوع تعليما تطبيقيا لنا، وتنبيها مدلَّلا من

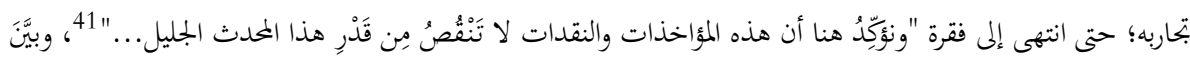

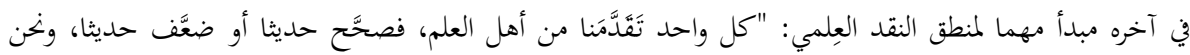

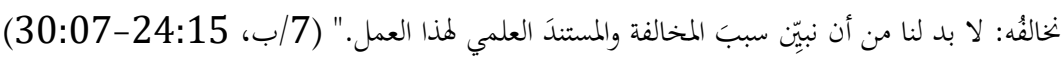

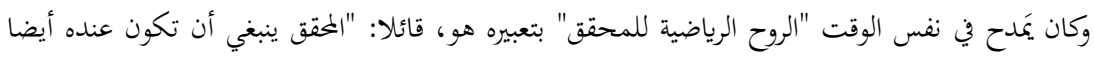

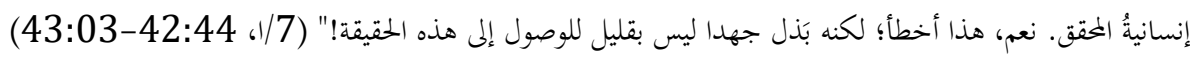

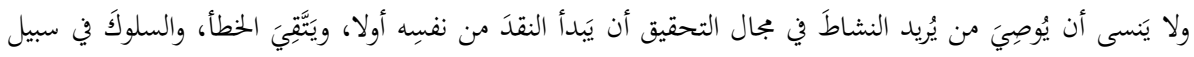

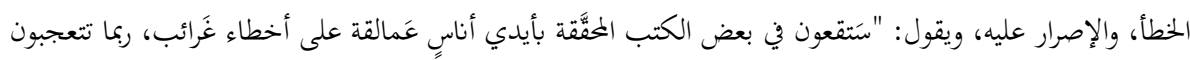

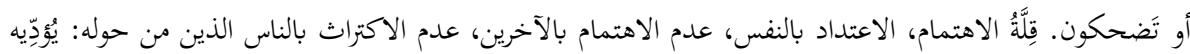

إلى مثل هذه الأخطاء." (7/ا، 45:50-45:20)

\section{2. ألاث صفحات من أيامي مع الشيخ شعيب الأرنؤوط}

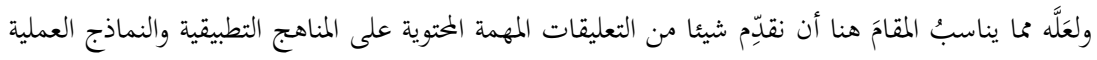

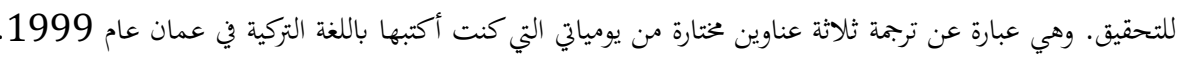

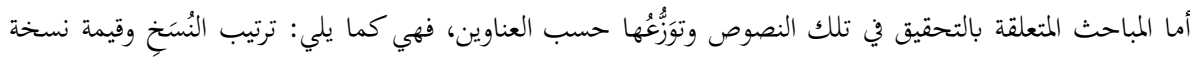

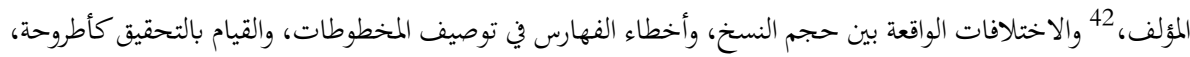

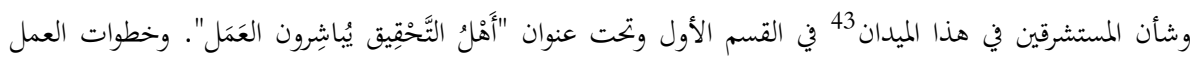

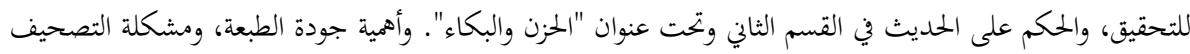

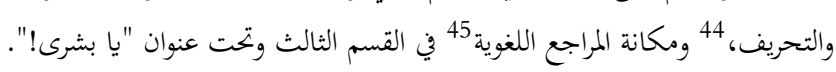

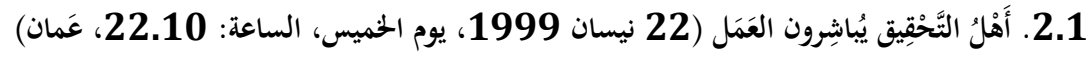

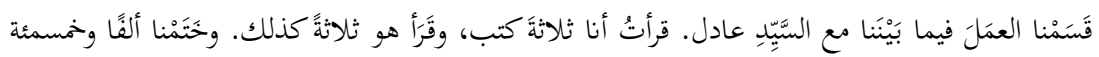

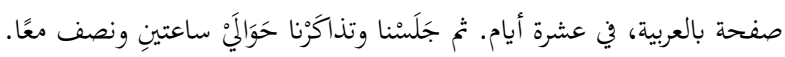

41 أحمد بن حنبل، المسند (تحقيق: شعيب الأزئوط والآخرون)، 150/1 (مقدمة المحقق).

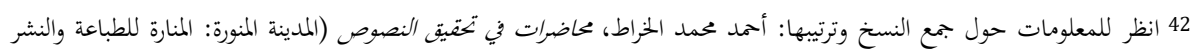

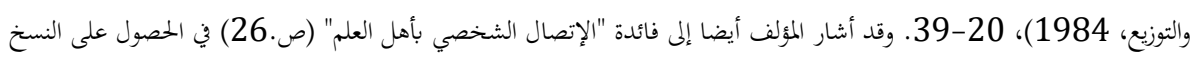

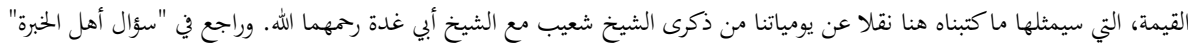

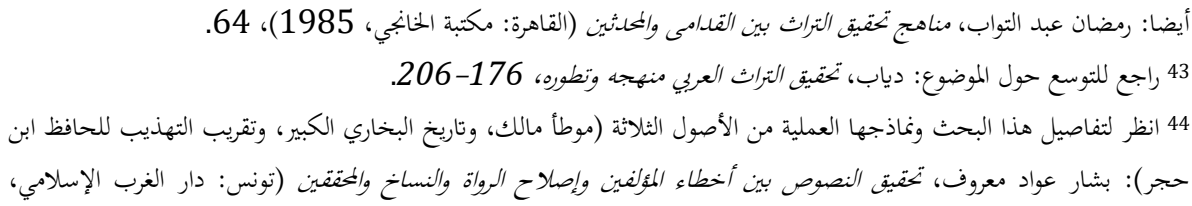

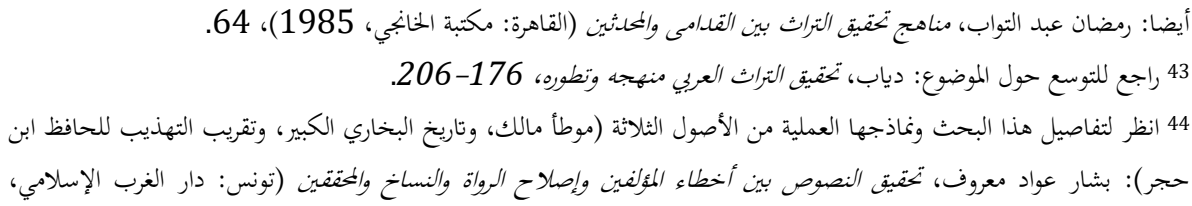

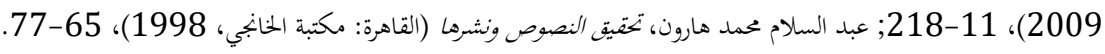

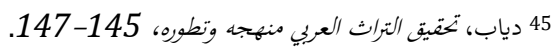


مكانة الممارسة في صناعة تحقيق النصوص: ثلاث صفحات من أيامي مع الشيخ شعيب الأرنؤوط

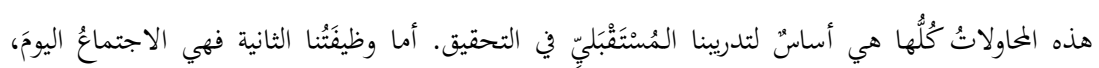

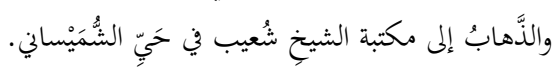

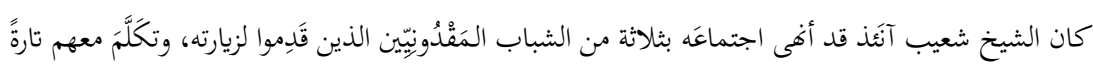

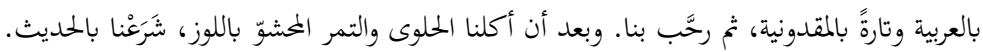

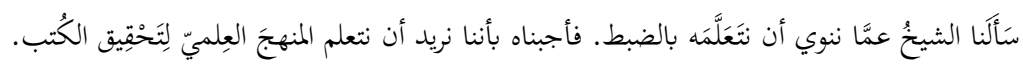

$$
\text { - إلى متى أنتم هنا؟ }
$$

- أربعة أشهر إن شاء اللهِ، شيخَنا.

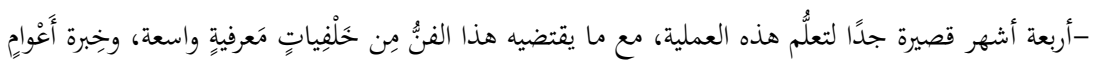

وأعوام.

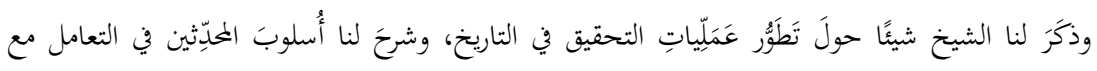

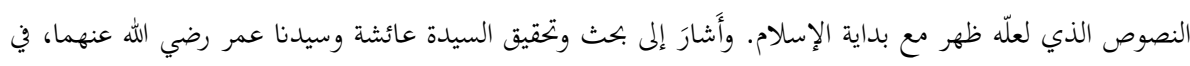

الأحاديث النبوية.

وأصرَّ على فكرة أننا -المسلمين- أنتجنا أساليبَ التحقيقِ بأنفسنا، ولم نأخذها عن المستشرقين. واستَتْهَهَ

$$
\text { بالقاضي عياض وكتابه الرائع: الإلماع إلى معرفة أصول الرواية وتقييد السماع. ألمان. }
$$

$$
\text { أربعون ورقة في ستة أشهر }
$$

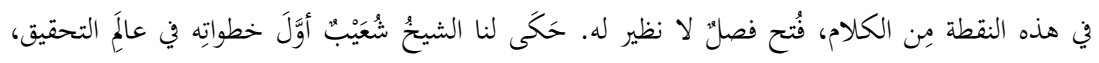

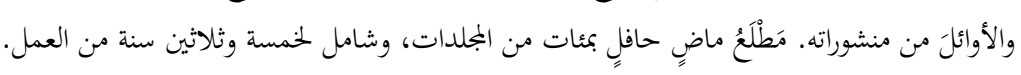

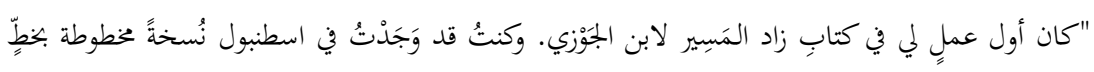

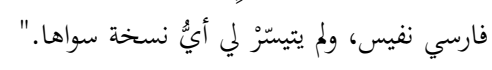

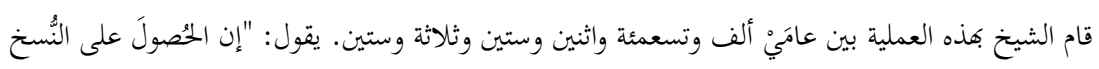

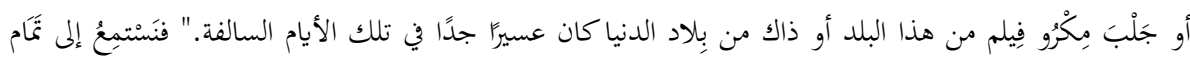

$$
\text { الكلام منه أيضا: }
$$

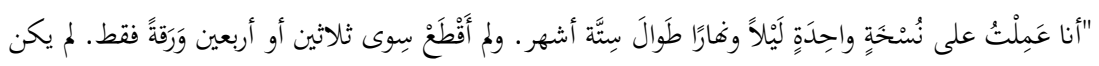

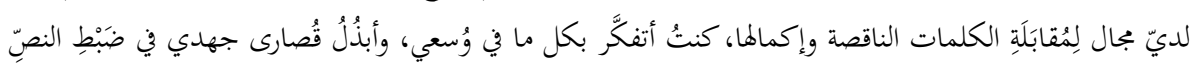

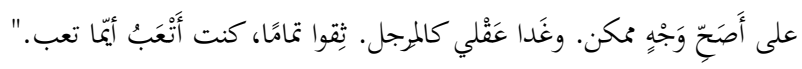

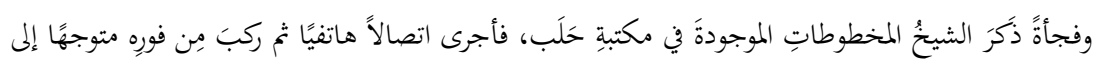

$$
\text { حلب ليلتقي هناك بصديقه الذي كنتُ قد أحبيتُه أيضًا: }
$$

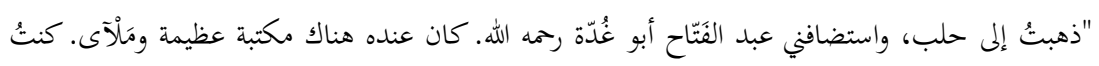


وكنتُ قد سمعتُ عن النهاية المأساويّة لمذه المكتبة من فم أبي غدة رمهه الله في قونية. حكى، آسِفًا، إزعاجَ نظام

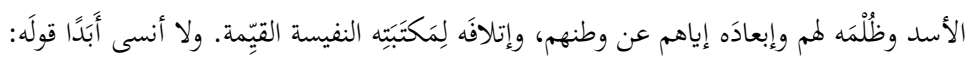

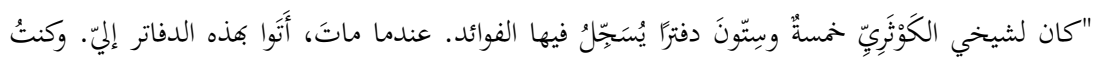

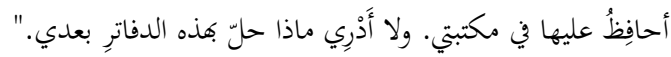

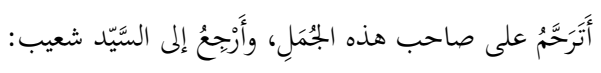

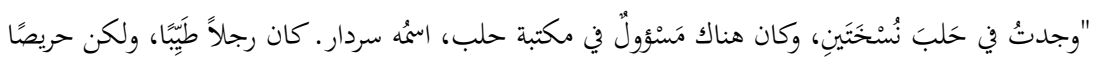

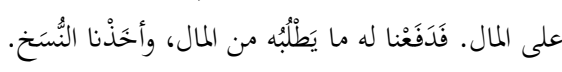

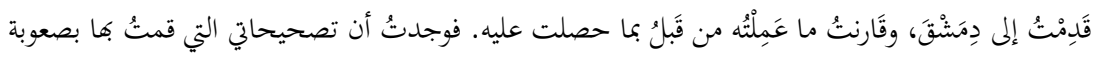

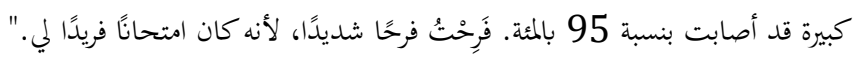
كان الشيخُ شعيب يذكُرُ صاحبَه بِخيَر:

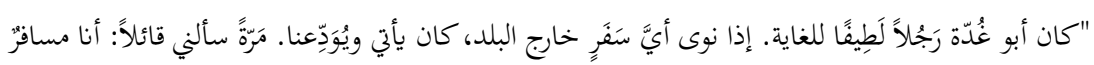

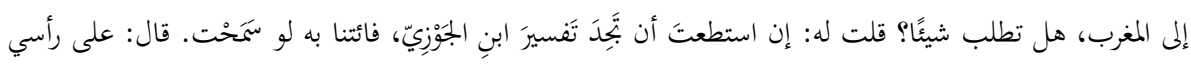

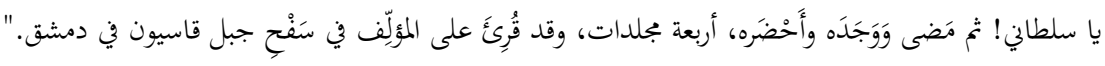

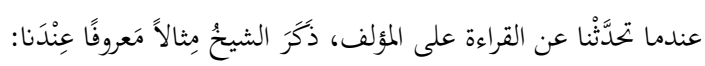

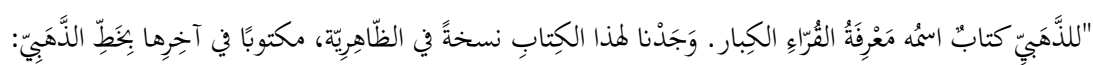

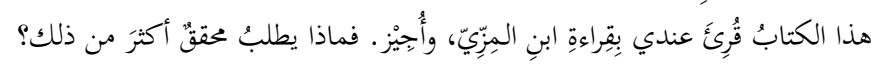

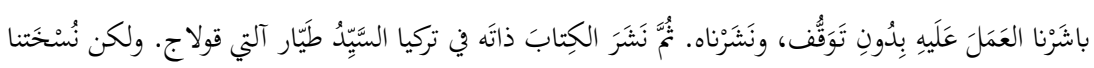

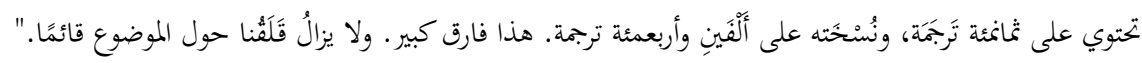

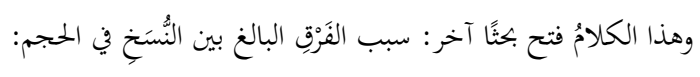

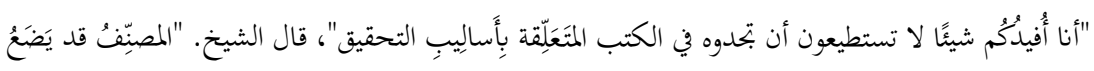

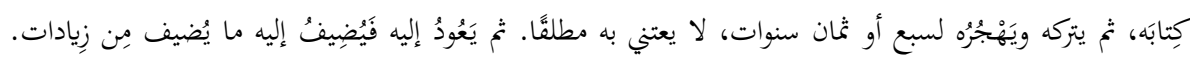

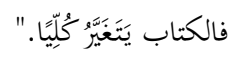
طبعًا، لا بُدَّل نا من الحصول على الحالة الأخيرة للكتاب، بالإضافة إلى الدِّقّة فيما بأتي مِن توجيهاتِ شيخِنا:

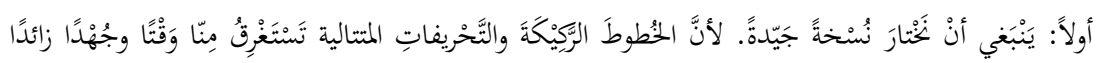

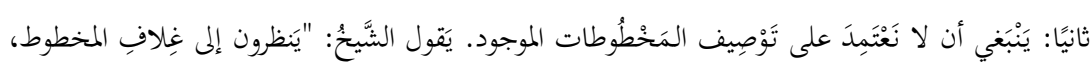

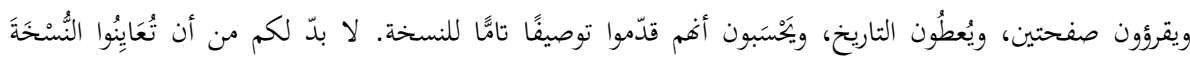
بالذّات." 
مكانة الممارسة في صناعة تحقيق النصوص: ثلاث صفحات من أيامي مع الشيخ شعيب الأرنؤوط

عِلميةٍٍ شتى. غير أنّ عليه أن يَعْمَل في مَنْدانِه.

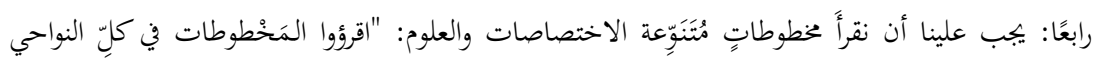

العلمية."

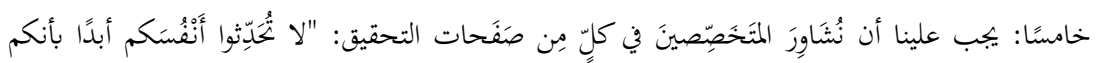

تَعَلمون، وبأنكم تَفْهمون، وبأنكم تحلون المشاكل. إن أشكلتُ عليكم نقطة، فاسألوا عنها."

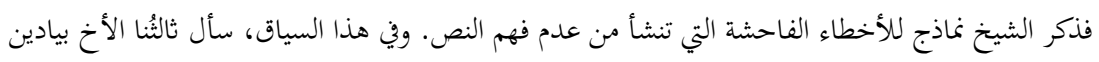

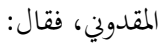

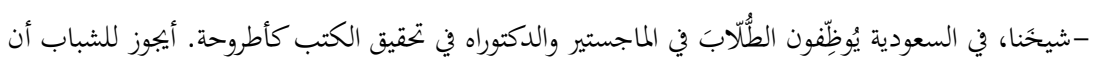

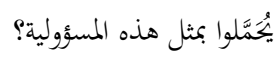

- نعم، يجوز أن يضطلعوا بهذه المسؤولية. ولكن بشرط: أن يكون الأستاذ المشرف خبيرًا، فينشَوَوا نَنْأَة عِلمية.

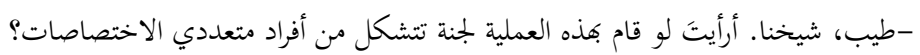

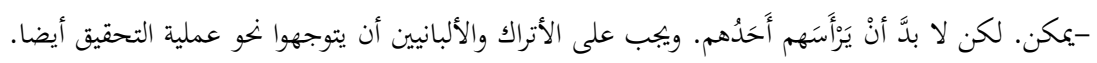

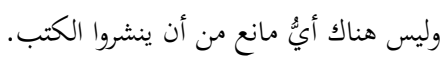

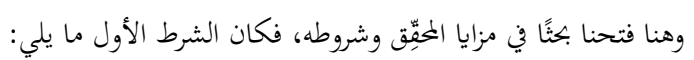

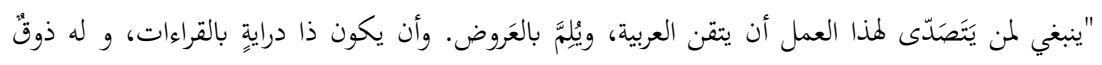

يستشعر به معاني اللسان العربي."

ويُهَرِّنُ الشيخُ من شأن المستَشْرِقِن ودَوْرِهم في هذا الميدان:

"يُشِيرون -أي المستشرقون- إلى الفروق بين النُّنَخ. ولكن عندما يأتي وقتُ الترجيح، يرسلون الكلمة الأصيلة

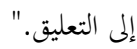

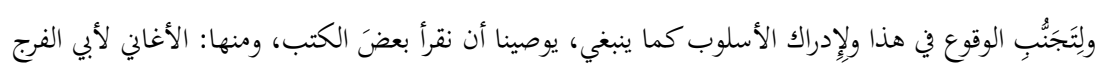

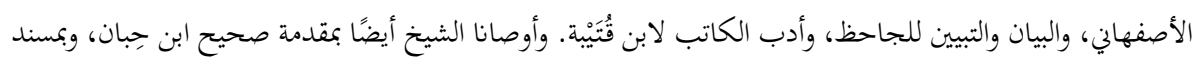

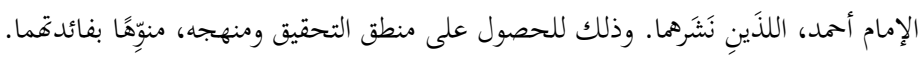

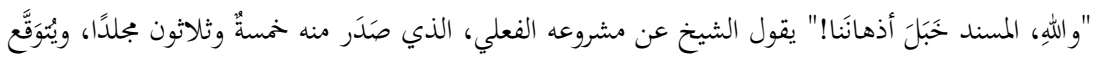

صُدورُ عَشرة مجلداتٍ أخرى منه.

وكان الله في عوفم.

2.2. الحزن والبكاء (6 أيلول 1999، بوكمان يوم الاثنين، الساعة: 05.53، صويلح)

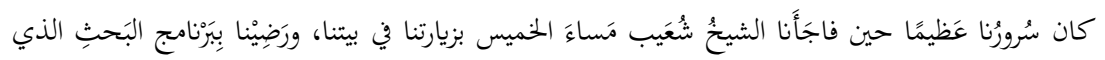

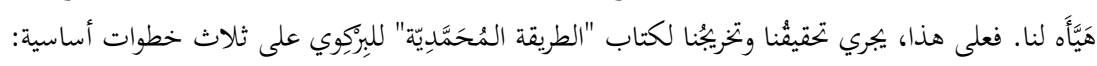

$$
\text { الأولى: تخريجُ الأحاديثِ والمُكْمُ عليها. }
$$




$$
\text { الثالثانية: ضَبْطُ الكَكِمَات المُشْكِلة بِدِقِّة. }
$$

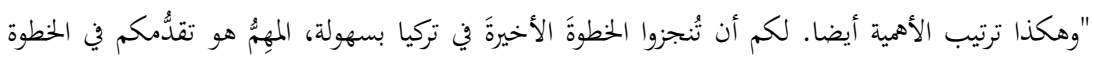
الأولى هنا." يقول شَيُْخنا.

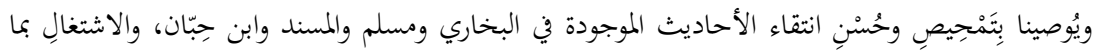

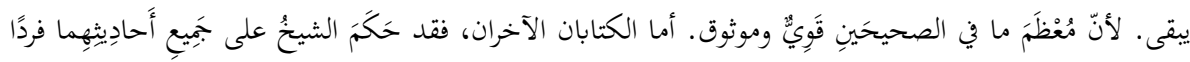

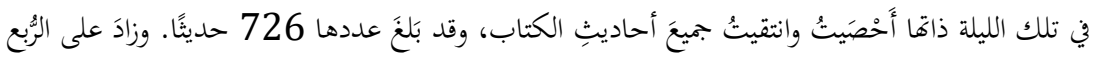

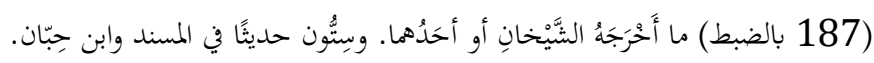

$$
\begin{aligned}
& \text { وكنتُ قد عَمِلْتُ على ثمانين منها من قبل. } \\
& \text { فبقيَ عندنا } 400 \text { حديثٍ ونيف. }
\end{aligned}
$$

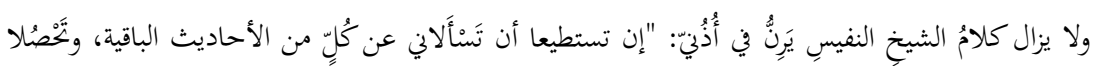

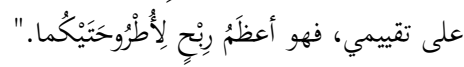

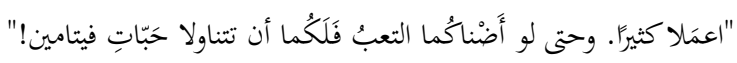

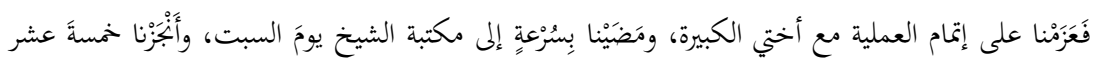

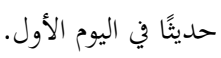

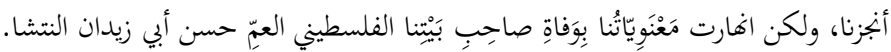

$$
\begin{aligned}
& \text { وانْنَلَبَ "بيت الحاجّ" المبتهِجِ بالأمس إلى "بيت عزاء". } \\
& \text { فإنا لله وإنا إليه راجعون. }
\end{aligned}
$$

2.3. يا بشرى! (21 أيلول 1999، يوم الثلاثاء، الساعة: 19.19، 19.19، صويلح)

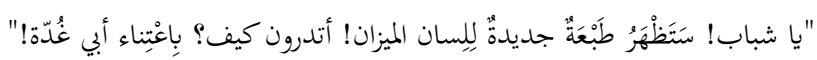

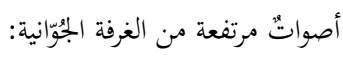

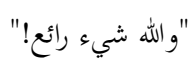

$$
\text { "مشروع حياة الشيخ عبد الفتاح!" }
$$

$$
\text { أضاف الأستاذ بسرور: }
$$

"أما المجلد العاشر والأخير، فُمُخَصَّصٌٌ للفَهَارِس."

$$
\text { با سلام! }
$$


مكانة الممارسة في صناعة تحقيق النصوص: ثلاث صفحات من أيامي مع الشيخ شعيب الأرنؤوط

كان النظام الجامعي لا يكاد يسمح لطالب العلم أن يطَّلِع على أمهات الكتب في مئات من المجلدات، فيبقى

$$
\text { عدد المصادر المقروءة والمطَّكَعِعليها عحدودًا. }
$$

فأنا على الرغم مِن مُواظبتي لمكتبة الكُلِّيّة، مواظبةً شِبةَ يومية، ومعرفتي بها مثل مُوَظظَِّيها، كأنني كنتُ في بحيرة

$$
\text { بيد أني وصلتُ هنا إلى بحري. }
$$

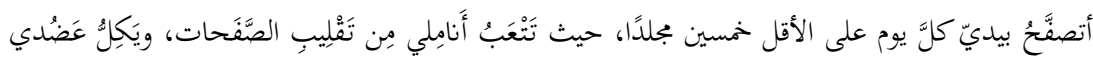

$$
\begin{aligned}
& \text { بَيْدَ أنّ الحال هذه كانت جَيّدة ويُمْتِعَة. والأجودُ: تعليمُ الشيخ إياي ما في السوق من الكتب. } \\
& \text { مثلاً، طبعة ممتازة: - مثاً } \\
& \text { - أستاذ! كأنَّ كتابَ السيّد خَلدون أحدب، المُسَمّى بِنَوائد تاريخ بغداد، كتابُّ حسن. }
\end{aligned}
$$

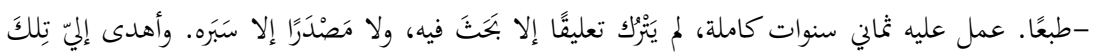

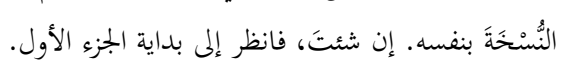

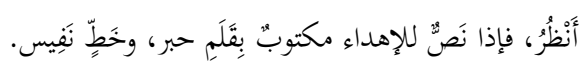

$$
\text { مثلاً، طبعة رديئة: }
$$

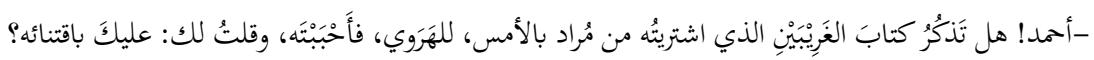

$$
\text { لا تَشْتَرِ هذا الكِتابَ أبدًا ها! }
$$

- خيرًا إن شاء الله شيخنا، لماذا؟

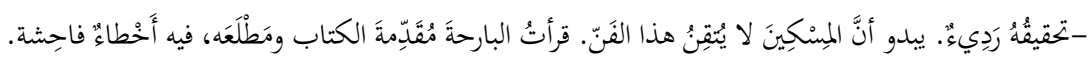

- أخطاء مثل ماذا أستاذي؟

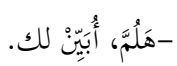

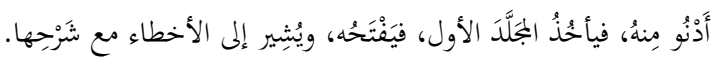

$$
\begin{aligned}
& \text { أولاً بعضُ الأخطاء في الحركات، } \\
& \text { تم تََْرِنفَاتُ في كَلِماتِ رئيسية، }
\end{aligned}
$$

ما هذا؟ البيت الأساسي في مادة (أبّ) قد فات، وأخَذَ مَوْقِعَه السطرُ التالي.

$$
\text { أي: قُطِع النَّصٌُ العَادِيُّ مِن مُنْتَصَفِه، وكُكِتبَ على شَكْلِ بيتٍ شِعريّ. }
$$

$$
\text { وأينَ البيت؟ وراء فقرتين/صفحة. }
$$

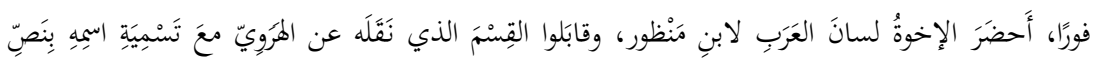




$$
\text { "غير معقول!" }
$$

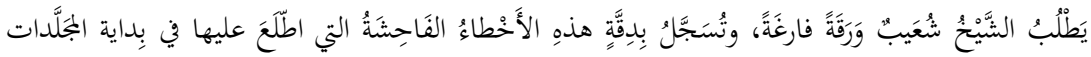

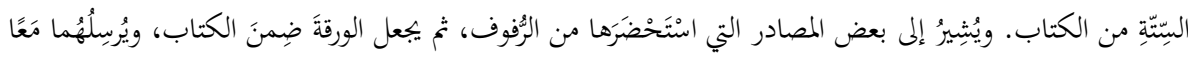

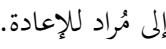

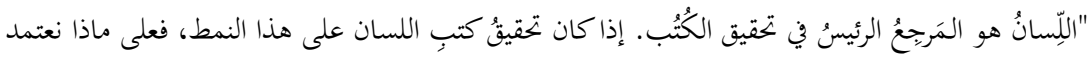

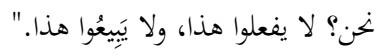

\section{الخايتة}

فمن النتائج الواضحة لهذا البحث أن الممارسة العملية لصناعة التحقيق لها مكانة متازةٌ لا بد من الإشارة إليها،

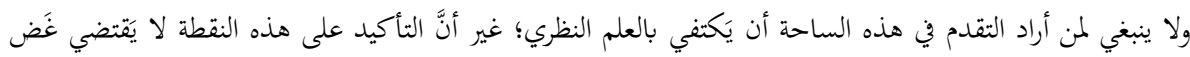

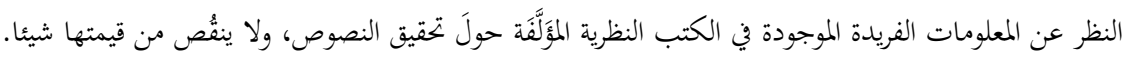

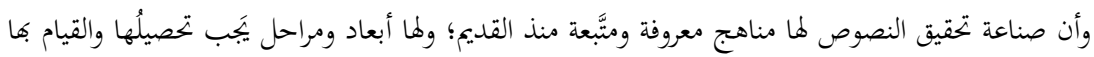

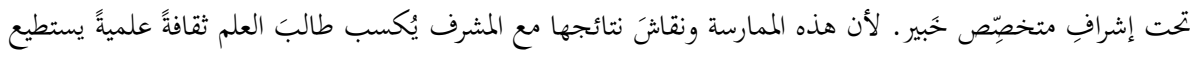

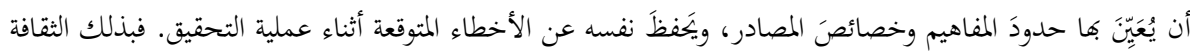

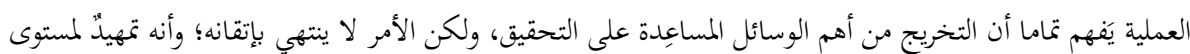

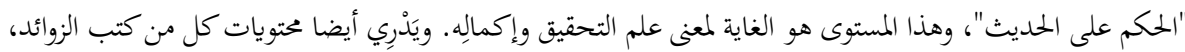

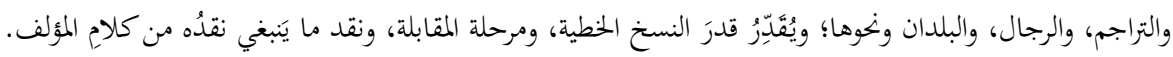

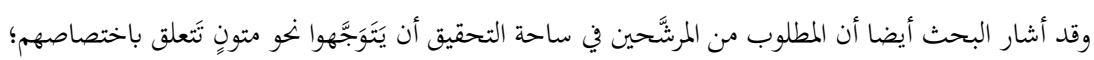

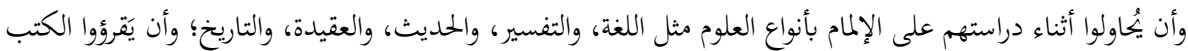

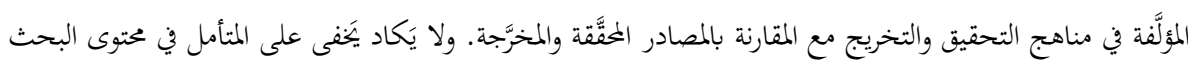

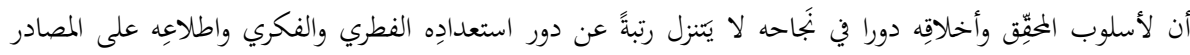
والمناهج. وقد احتوى البحثُ أيضا على بعض الأمثلة التي تَدُلُ على فوائد تسجيل تجاربٍ كبار أهل العلم، وكتابِّ.

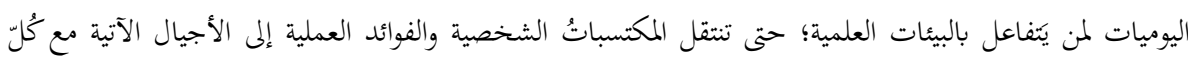
جوانبها الإبابية والسلبية. فكان الشيخ المحقق شعيب الأرنؤوط رمه الله نموذجا متثازا في هذا الباب وأمثالِه، وشخصيةً مترمة في صنعتِه

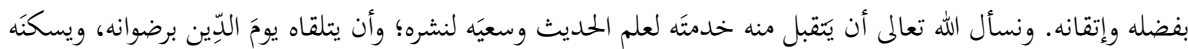
فسيح جناته. 
مكانة الممارسة في صناعة تحقيق النصوص: ثلاث صفحات من أيامي مع الشيخ شعيب الأرنؤوط

المصادر والمراجع

Martı, Huriye. Birgili Mehmed Efendi'nin Hadisçiliği ve et-Tarikatü'lMuhammediyye (Tahkik ve Tahlil). Konya: Selçuk Üniversitesi Sosyal Bilimler Enstitüsü, Doktora Tezi, 2005.

Ürkmez, Ahmed. Kadızadeliler-Sivasiler Tartışmalarının Hadis İlmine Etkisi ve İdrakü'l-Hakika Örneği. Konya: Selçuk Üniversitesi Sosyal Bilimler Enstitüsü, Yüksek Lisans Tezi, 2000.

Yıldırım, Enbiya. Hadisler ve Zihinlerdeki Sorular: Büyük Muhaddis Şuayp Arnavut'la Söyleşi. İstanbul: Rağbet Yayınları, 2011.

$$
\begin{aligned}
& \text { أحمد بن حنبل، أبو عبد الله الشيباني. المسند (تحقيق: أحمد عحمد شاكر). القاهرة: دار الحديث، } 1995 . \\
& \text { أممد بن حنبل، أبو عبد الله الشيباني. المسند (تخقيق: شعيب الأزئوط والآخرون). بيروت: مؤسسة الرسالة، } 1999 . \\
& \text { ابن الجوزي، جمال الدين أبو الفرج عبد الرمن بن علي. زاد المسير في علم التفسير (تحقيق: محمد زهير الشاويش، }
\end{aligned}
$$

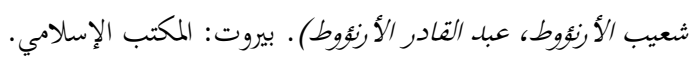

$$
\begin{aligned}
& \text { ابن الملقن، أبو حفص عمر بن علي. البدر المنير في تخريج أحاديث الشرح الكبير (تعقيق: جمال محمد السيد). } \\
& \text { الرياض: دار العاصمة، 2009. } \\
& \text { ابن بلبان، علاء الدين علي الفارسي. الإحسان في تقريب صحيح ابن حبان (تحقيق: شعيب الأزئوط). بيروت: } \\
& \text { مؤسسة الرسالة، } 1988 . \\
& \text { ابن حبان، أبو حاتم حمد البستي. كتاب المجروحين من المحدثين (تعقيق: حمدي عبد المجيد السلفي. الرياض: دار } \\
& \text { الصميعي، } 2000 . \\
& \text { ابن قدامة، عبد الله بن أحمد. الوافي في تخريج أحاديث الكافي (تخريج: خالد بن ضيف الله). دمشق: دار المنهاج }
\end{aligned}
$$

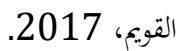

$$
\begin{aligned}
& \text { ابن قيم الجوزية، محمد بن أبي بكر. زاد المعاد في هدي خير العباد (تعقيق: شعيب الأنؤوط، عبد القادر الأزئوط). } \\
& \text { بيروت: مؤسسة الرسالة، } 1998 . \\
& \text { البركوي، حممد بن بير علي. الطريقة المحمدية والسيرة الأحمدية (تعقيق: محمد حسني مصطفى). حلب: دار القلم } \\
& \text { العربي، } 2002 . \\
& \text { البغوي، الحسين بن مسعود. شرح السنة (تعقيق: شعيب الأرئوط، محمد زهير الشاويش). بيروت: المكتب الإسلامي، } \\
& .1983 \\
& \text { الحلبي، أحمد بن يوسف السمين. الدر المصون في علوم الكتاب المكنون (تعقيق: أحمد عحمد الخراط). دمشق: دار }
\end{aligned}
$$




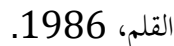

الحراط، أحمد محمد. محاضرات في تحقيق النصوص. المدينة المنورة: المنارة للطباعة والنشر والتوزيع, 1984. الذهبي، شمس الدين أبو عبد الله عحمد بن أممد. سير أعلام النبلاء (تعقيق: شعيب الأرثوط وآخرون). بيروت:

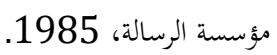
الذهبي، شمس الدين أبو عبد الله حممد بن أممد. معرفة القراء الكبار على الطبقات والأعصار (تعقيق: بشار عواد معروف، شعيب الأزئوط، صالم مهادي عباس)، بيروت: مؤسسة الرسالة، 1988. الزبيق، إبراهيم. المحدث العلامة الشيخ شعيب الأزئوط: سيرته في طلب العلم وجهوده في تحقيق التراث. بيروت: دار البشائر الإسلامية، 2012. الزركشي، بدرالدين. الإجابة لإيراد ما استدركته عائشة على الصحابة (التحقيق: د.بنيامين أرول؛ التقلديم: المحلث

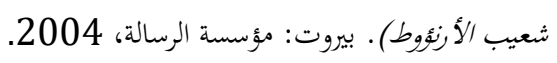
الطحان، محمود. أصول التخريج ودراسة الأسانيد. الرياض: مكتبة المعارف للنشر والتوزيع، 1996. العسقلاني، ابن حجر .تقريب التهذيب (عناية: عادل مرشد). بيروت: مؤسسة الرسالة، 1999.

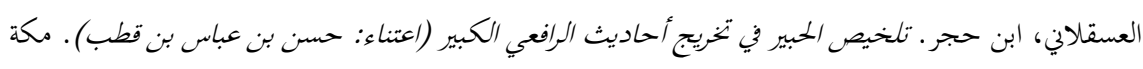
المكرمة: مؤسسة قرطبة، 1995. العسقلاني، ابن حجر ف فتح الباري بشرح صحيح البخاري (إشراف: شعيب الأزئوط، عادل مرشد؛ تحقيق: أحما. برهوم، حمد كامل قره بللي، هيثم عبد الغنور). بيروت: الرسالة العالمية، 2013. الفضلي، عبد المادي. تعقيق التراث. جدة: مكتبة العلم، 1982. اللكنوي، محمد بن عبد الحي. التعليق الممجد على موطأ الإمام محمد (تحقيق: شعيب الأزئوط، محمد نعيم

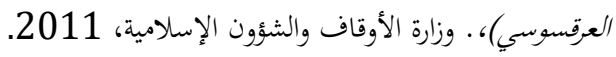
المناوي، محمد عبد الرؤوف. فيض القدير شح الجامع الصغير من أحاديث البشير النذير (تصحيح: أحمد عبد

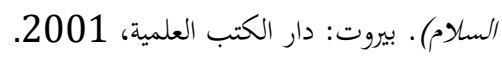
المنجد، صلاح الدين. قواعد تحقيق المخطوطات. بيروت: دار الكتاب الجديد، 1982. النووي، محيي الدين بن شرف. كتاب المجموع شرح المهنب للشيرازي (تعقيق: محمد نجيب المطيعي). جدة: مكتبة الإرشاد. 
مكانة الممارسة في صناعة تحقيق النصوص: ثلاث صفحات من أيامي مع الشيخ شعيب الأرنؤوط شاكر، أحمد محمد. تصحيح الكتب وصنع الفهارس المعجمة وكيغية ضبط الكتاب وسبق المسلمين الأفنج في ذلك (إعتناء: عبد الفتاح أبو غلدة). القاهرة: مكتبة السنة، 1994.

عبد التواب، رمضان. مناهج تحقيق التراث بين القدامى والمحدثين. القاهرة: مكتبة الخناني، 1985. عُسيلان، عبد الله بن عبد الرحيم. تحقيق المخطوطات بين الواقع والنهج الأمثل. الرياض: مطبوعات مكتبة الملك فهد الوطنية، 1994. معروف، بشار عواد. تحقيق النصوص بين أخطاء المؤلغين وإصلاح الرواة والنساخ والمعقعين. تونس: دار الغرب الإسلامي، 2009.

هارون، عبد السلام محمد. تحقيق النصوص ونشرها . القاهرة: مكتبة الخانجي، 1998.

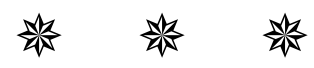




\title{
TAHKIKK İŞLMİNDE UYGULAMANIN YERİ VE ÖNEMİ: MUHAKKİK ŞUAYB EL-ARNAVUT'TAN ÜÇ HÂTIRA
}

\author{
Ahmed ÜRKMEZa
}

\section{Geniş Öz}

Çalışma bir giriş ve iki bölümden oluşmaktadır. Giriş bölümünde tahkik işleminin bireysel birikim ve grup çalışmasını aynı anda gerektiren karakterinden bahsedilmiştir. Alanının önemli uzmanlarından olan Muhakkik Şuayb el-Arnavut'un yayınladığı temel eserlerin ve Amman'da kurduğu tahkik merkezinin niteliklerine değinilmiștir. Bu bağlamda, özellikle hayatının son yirmi yılında Amman'da kendisiyle çalışma imkânı bulan pek çok Türk akademisyenin yetişmesine doğrudan katkıda bulunduğu vurgulanmış, söz konusu isimlere ve yaptıkları bilimsel çalışmalara örnekler verilmiştir. Giriş bölümünde ayrıca Muhakkik Şuayb elArnavut'un kısa biyografisine ve Tefsir, Hadis ve Siyer gibi alanlarda tahkik ettiği başlıca eserlere de yer verilmiştir. Makale içinde yapılacak tespit ve alıntıların, kendisinden 1999 yılında Amman'da bir grup Türk akademisyen adayı olarak on beş oturumda almış olduğumuz özel tahkik derslerinin ses kayıtlarına ve tahkik merkezinde yaptığımız uygulamalı eğitime dayandığı da burada belirtilmiștir.

Makalenin ilk bölümü beş alt başlıktan oluşmaktadır. "Tahkik sanatının kapsamı ve gereklilikleri" başlıklı ilk alt başlıkta, tahkik işleminin mahiyeti, aşamaları ve her aşamada dikkat edilmesi gereken hususlar hakkında Muhakkik Şuayb el-Arnavut'tan aldığımız bazı bilgilerin değerlendirmesi yapılmıştır. Tahriç çalışması ve tahkikteki yeri, hadis hakkında sıhhat hükmü vermenin zorluğu, tahricin tek başına yeterli bir düzeyi ifade etmediği gibi temel fikirlere temas edilmiştir. Normal şartlar altında tek başına bir makale, hatta kitap konusu olan bu alt başlık, sadece bu çalışmayı ilgilendiren

\footnotetext{
a Doç. Dr., Pamukkale Üniversitesi, aurkmez@pau.edu.tr
} 
boyutları ile sınırlanarak kısa tutulmaya çalışılmıştır. Yine de tahkikte nüsha seçimi, yazma nüshalar arası mukabele işleminin vazgeçilmezliği ve tahkik yapacak kişinin temel ilimler üzerinde genel bir kültüre sahip olmasının yararı gibi uygulamaya dair ek meseleler gündeme getirilmiştir.

"Teorik bilgiyle yetinmemek" başlığı altında ise daha ziyade Muhakkik Şuayb el-Arnavut'un bu yöndeki ısrarlı tercihinin yansımaları görülecektir. Kendisinin tahkik konusunda niçin bir kitap yazmadığı ve uygulamada kalmayı teorik bilgiye neden tercih ettiği sorusuna cevap aranacaktır. $\mathrm{Bu}$ madde bağlamında tahkik bürosunda yaşadığımız somut tecrübelerden birine de örnek olarak yer verilecektir.

"Öğrenciye tahkikin kaynaklarını tanıtmak" başlığı altında, kütüphane ortamında ve uygulamaya dayalı bir tahkik eğitiminin en temel yararlarından birine dikkat çekilmektedir. Teorik tahkik eserlerinin yöntem bilgisinin yanında kaynak tanıtımlarını da içerdiği, ancak söz konusu kaynaklara doğrudan erişimin ilave gözlem imkânları oluşturduğu açıktır. Bu noktada öğrenciye kaliteli baskı ile özensiz baskı arasındaki farkı göstermek, edinme veya inceleme bakımından öncelik vermesi gereken kaynakları belirtmek, kendi yayınladığı eserlerden yeri geldiğinde hediye etmek, Muhakkik Şuayb el-Arnavut'un kendisini tanıyanlarca yakından bilinen özellikleridir. Tahkik alanında yazılmış teorik eserler ve müelliflerini tanıtmasının yanında, tahkikte ihtiyaç duyulacak klasik eserlerin muhtevaları hakkında bilgi vermesi de burada kaydedilmelidir.

"Tahriç kavramını sağlam bir zihnî temele dayandırmak" ifadesi ise, kaynakların tekil olarak değerlendirilmesinden bir adım ilerisine sşık tutmaktadır. Bu boyut, ilgili eserlerin tahriç işlemi sırasında taşıdıkları anlamın tarih ve literatür verilerinden hareketle öğrenciye kavratılmasını kapsamaktadır. Nebevi sünnetin İslâm'daki yeri, hadislerin yazıya geçirilme süreci, siyasi ve mezhebi ihtilafların hadis uydurma faaliyetleri üzerindeki etkisi, zayıf hadislerin delil olması için öne sürülen şartlar gibi pek çok bilginin üzerine "tahriç işlemine duyulan ihtiyaç" bina edilmiş olacaktır.

"İhtiyaç hâlinde tenkide başvurmaktan çekinmemek" başlı̆̆ altında ise tenkit kültürünün tahkikteki yerine değinilmiștir. Aklın etkin kullanımının orijinalliği beraberinde getirdiği ve gerek metindeki hataların tashihinde gerekse müellifin görüşlerinin tenkidinde buna yer vermek gerektiği belirtilmiştir. Ayrıca Muhakkik Şuayb el-Arnavut'un aklî çıkarımları çok önemseyen tavrına işaret edilmiş ve hadis alanında da akla dayalı tenkit yapılabileceği şeklindeki görüşüne örnekler verilmiştir. Bununla birlikte dini alanda aklın kullanımında öngörülecek ölçülerin kendisine göre neler 
olabileceğine dair kısa bir tartışmaya da temas edilmiştir. Hadis alanında hiçbir bilgisi olmamakla birlikte sırf kişisel görüşüne uygun düşmediği için hadisleri inkâr etmenin burada sözü edilen aklî tenkitle ilişkisinin olmadığı vurgulanmıştır. Kişinin sevdiği bir ilim adamının hatasını da yeri geldiğinde tenkit edebilmesine ve mesafeli durduğu kişinin olumlu yönünü takdir edebilmesine dair kimi örnekler de yine Muhakkik Şuayb el-Arnavut özelinde dile getirilmiştir.

Makalenin ikinci bölümünde, Amman'da Türkçe tutmuş olduğumuz günlüklerden, Muhakkik Şuayb el-Arnavut ve tahkik tecrübeleri hakkında doğrudan bilgi içeren üç bölümün Arapça çevirileri sunulmuştur. Buradaki amaç, kaynakları tanıma, konunun uzmanıyla detayları tartışma ve bir tahkik bürosunun iç işleyişine vâkıf olma gibi hususların yanında, ilimler tarihinin tahkik sayfasına yaşanmışlığı olan canlı bir şahitlikle not düşmektir. Ancak altını çizerek belirtmeliyiz ki, bizim bu makalede yaptığımız, merhum Muhakkik Şuayb el-Arnavut'un ilmî mirasının hak ettiği inceleme hacminin binde biri bile olmayıp, bu konuda asıl büyük birikim ve dolayısıyla tahkik yöntemlerini yazma sorumluluğu, kendisiyle yıllarca çalışan değerli mesai arkadaşlarına aittir.

Anahtar Kelimeler: Hadis, Tahkik, Tahriç, İlmî Tenkit, Muhakkik Şuayb elArnavut. 


\title{
THE PLACE AND IMPORTANCE OF THE APPLICATION IN THE CRITICAL EDITION PROCESS: THREE MEMORIES FROM SHAYKH SHUAIB AL ARNA'UT
}

\author{
Ahmed ÜRKMEZa
}

\section{Extended Abstract}

The study consists of an introduction and two parts. In the introduction, the character of the critical edition process that requires individual knowledge and group work at the same time is mentioned. The main works published by Shaykh Shuaib al Arna'ut one of the important experts in the area and the qualifications of the investigation center he established in Amman were mentioned. In this context, it was emphasized that he directly contributed to the training of many Turkish academicians who had the opportunity to work with him in Amman especially in the last twenty years of his life and examples were given to these names and their scientific studies. In the introduction part, the short biography of Shaykh Shuaib al Arna'ut and the main works he investigated in areas such as Tafsir, Hadith and Siyer are also included. It is also stated here that the determinations and citations to be made in the article are based on the voice recordings of the private critical edition lessons we received from him in fifteen sessions as a group of Turkish academician candidates in Amman in 1999 and the practical training we did in the critical edition center.

The first part of the article consists of five subtitles. In the first subtitle titled "Scope and requirements of the art of critical edition" some of the information we received from Shaykh Shuaib al Arna'ut about the nature, stages and points to be considered at every stage of the critical edition process was evaluated. Basic ideas were touched upon such as the study of takhrij and its place in critical edition, the difficulty of deciding on the hadith

a Assoc. Prof., Pamukkale University, aurkmez@pau.edu.tr 
and that the takhrij alone does not represent a sufficient level. Although this title is the subject of a stand-alone article or even a book under normal conditions, it has been tried to be kept short by restricting it to the dimensions that concern this study. Nevertheless, additional practical issues were raised, such as the selection of copies in the investigation, the indispensability of the response between manuscripts, and the benefit of the researcher having a general culture on basic sciences.

Under the heading of "not being contented with theoretical knowledge" the reflections of Shaykh Shuaib al Arna'ut's insistent preference in this direction will be seen. The question of why he did not write a book on investigation and why he preferred to remain in practice instead of theoretical knowledge will be sought. In the context of this issue, a place will be given as an example for one of the concrete experiences we had in the critical edition office.

Under the heading "Introducing the student to the sources of critical edition", one of the main benefits of an application-based critical edition education in the library environment is highlighted. It is clear that theoretical critical edition books include source introductions in addition to methodology, but direct access to these sources creates additional observation opportunities. At this point, showing the student the difference between high quality printing and sloppy printing, indicating the resources that should be prioritized in terms of acquisition or review, giving gifts from his own published works are the characteristics of Shaykh Shuaib al Arna'ut that are well known to those who know him. It should be noted here that besides introducing the theoretical works written in the field of critical edition and their authors, it also gives information about the contents of the classical works that will be needed in the critical edition.

The expression "basing the concept of takhrij on a solid mental foundation" also sheds light on one step ahead of evaluating the sources individually. This dimension includes the comprehension of the meaning of the related works during the takhrij process, based on the historical and literature data. The place of Prophetic Sunnah in Islam, the process of writing down hadiths, the effect of political and sectarian disputes on hadith fabrication activities and the conditions put forward for weak hadiths to be evidence, will be built on the "need for takhrij".

Under the heading "Not hesitating to resort to criticism in case of need", the place of criticism culture in critical edition was mentioned. It has been stated that the effective use of reason brings along originality and that it should be included both in the correction of the errors in the text and in the criticism of 
the author's views. In addition, the attitude of Shaykh Shuaib al Arna'ut who attaches great importance to rational inferences is pointed out and examples of his opinion that rational criticism can be made in the field of hadith are also included. Along with this, a brief discussion about what the measures to be predicted in the use of reason in the religious field could be according to him was also touched. It has been emphasized that the person's denial of hadiths just because they do not fit his personal opinion, although he has no knowledge of the hadith, is not related to the rational criticism mentioned here. Some examples of the fact that a person can criticize the mistake of a scientist he loves and appreciate the positive side of the person with whom he stands distant are also mentioned in the case of Shaykh Shuaib al Arna'ut. In the second part of the article, the Arabic translations of three parts of the diaries we wrote in Turkish in Amman, which contain direct information about Shaykh Shuaib al Arna'ut and his critical edition experiences are presented. The aim here is to make a note with a live witness that has been experienced on the critical edition page of the history of sciences, in addition to the issues such as getting to know the sources, discussing the details with the expert on the subject and knowing the internal functioning of an critical edition office. However, we should underline that we have not made even one thousandth of the study that we have done in this article, which is deserved by the scientific heritage of Shaykh Shuaib al Arna'ut and the real experience on this subject and therefore the responsibility to write the critical edition methods belongs to his valuable colleagues who have worked with him for years.

Keywords: Hadith, Critical Edition Process, Takhrij, Scientific Criticism, Shaykh Shuiab al Arna'ut.

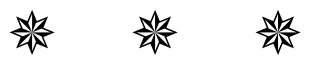

